

\title{
Extensive exploration of a novel rat model of Parkinson's disease using partial 6-hydroxydopamine lesion of dopaminergic neurons suggests new therapeutic approaches
}

Steven Vetel, Sophie Serriere, Johnny Vercouillie, Jackie Vergote, Gabrielle Chicheri, Jean-Bernard Deloye, Frédéric Dollé, Sylvie Bodard, Claire Tronel, Lydie Nadal-Desbarats, et al.

\section{- To cite this version:}

Steven Vetel, Sophie Serriere, Johnny Vercouillie, Jackie Vergote, Gabrielle Chicheri, et al.. Extensive exploration of a novel rat model of Parkinson's disease using partial 6-hydroxydopamine lesion of dopaminergic neurons suggests new therapeutic approaches. Synapse, 2019, 73 (3), pp.e22077. 10.1002/syn.22077 . inserm-02458381

\section{HAL Id: inserm-02458381 https://www.hal.inserm.fr/inserm-02458381}

Submitted on 31 Jan 2020

HAL is a multi-disciplinary open access archive for the deposit and dissemination of scientific research documents, whether they are published or not. The documents may come from teaching and research institutions in France or abroad, or from public or private research centers.
L'archive ouverte pluridisciplinaire HAL, est destinée au dépôt et à la diffusion de documents scientifiques de niveau recherche, publiés ou non, émanant des établissements d'enseignement et de recherche français ou étrangers, des laboratoires publics ou privés. 


\section{Synapse}

WILEY-

BLACKWELL

\section{Extensive exploration of a novel rat model of Parkinson's disease using partial 6-hydroxydopamine lesion of dopaminergic neurons suggests new therapeutic approaches}

\begin{tabular}{|c|c|}
\hline Journal: & Synapse \\
\hline Manuscript ID & SYN-18-0053.R1 \\
\hline Wiley - Manuscript type: & Research Article \\
\hline Date Submitted by the Author: & $\mathrm{n} / \mathrm{a}$ \\
\hline Complete List of Authors: & $\begin{array}{l}\text { Vetel, Steven; UMR 1253, iBrain, Université de Tours, Inserm, Tours, } \\
\text { France } \\
\text { Sérrière, Sophie; UMR 1253, iBrain, Université de Tours, Inserm, Tours, } \\
\text { France } \\
\text { Vercouillie, Johnny; UMR 1253, iBrain, Université de Tours, Inserm, Tours, } \\
\text { France; Inserm CIC1415 } \\
\text { Vergote, Jackie; UMR 1253, iBrain, Université de Tours, Inserm, Tours, } \\
\text { France } \\
\text { Chicheri, Gabrielle; UMR 1253, iBrain, Université de Tours, Inserm, Tours, } \\
\text { France } \\
\text { Deloye, Jean-Bernard; Zionexa, Paris, France } \\
\text { Dollé, Frédéric; CEA, Institut des Sciences du Vivant Frédéric Joliot, SHFJ, } \\
\text { Université Paris-Saclay } \\
\text { Bodard, Sylvie; UMR 1253, iBrain, Université de Tours, Inserm, Tours, } \\
\text { France } \\
\text { Tronel, Claire; UMR 1253, iBrain, Université de Tours, Inserm, Tours, } \\
\text { France } \\
\text { Nadal-Desbarats, Lydie; UMR 1253, iBrain, Université de Tours, Inserm, } \\
\text { Tours, France } \\
\text { Lefèvre, Antoine; UMR 1253, iBrain, Université de Tours, Inserm, Tours, } \\
\text { France } \\
\text { Emond, Patrick; UMR 1253, iBrain, Université de Tours, Inserm, Tours, } \\
\text { France; CHRU, Tours, France } \\
\text { Chalon, Sylvie; UMR 1253, iBrain, Université de Tours, Inserm, Tours, } \\
\text { France }\end{array}$ \\
\hline Keywords: & $\begin{array}{l}\text { Neuroinflammation, PET imaging, metabolomics, dopamine transporter, } \\
\text { TSPO }\end{array}$ \\
\hline Abstract: & $\begin{array}{l}\text { Parkinson's disease (PD) is characterized by the degeneration of } \\
\text { dopaminergic (DA) neurons constituting the nigrostriatal pathway. } \\
\text { Neuroinflammation, related to microglial activation, plays an important role } \\
\text { in this process. Exploration of animal models of PD using neuroimaging } \\
\text { modalities allows to better understand the pathophysiology of the disease. } \\
\text { Here, we fully explored a moderate lesion model in the rat in which 6- }\end{array}$ \\
\hline
\end{tabular}


Page 1 of 45

Synapse

hydroxydopamine was unilaterally delivered in 3 sites along the stratum. The degenerative process was assessed through in vive Positron Emission Tomography (PET) imaging and in vito autoradiographic quantitation of the striatal dopamine transporter (DAT) and immunostaining of tyrosine hydroxylase (TH). The microglial activation was studied through in vito autoradiographic quantitation of the $18 \mathrm{kDa}$ translocator protein (TSPO) in the stratum and CD 11b staining in the SN. In addition, a targeted metabolomics exploration was performed in both these structures using mass spectrometry coupled to HPLC. Our results showed a reproducible decrease in the striatal DAT density associated with a reduction in the number of TH-positive cells in the $\mathrm{SN}$ and stratum, reflecting a robust moderate degeneration of nigrostriatal DA neurons. In addition, we observed strong microglia activation in both the stratum and SN ipsilateral to the lesion, highlighting that this moderate degeneration of DA neurons was associated with a marked neuroinflammation. Our metabolomics studies revealed alterations of specific metabolites and metabolic pathways such as carnitine, arginine/proline and histidine metabolisms. These results bring new insights in the PD mechanism knowledge and new potential targets for future therapeutic strategies.

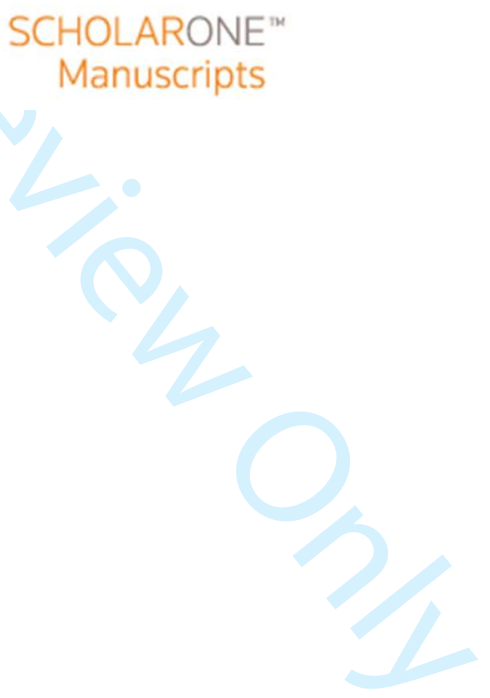




\begin{tabular}{|c|c|c|c|c|}
\hline Metabolic pathway & Match Status & FDR & Metabolites & FC ratio \\
\hline \multirow{7}{*}{$\begin{array}{l}\text { Arginine and } \\
\text { Proline metabolism }\end{array}$} & \multirow[t]{7}{*}{$7 / 44$} & \multirow[t]{7}{*}{0,0090661} & L-Ornithine & 0.91 \\
\hline & & & L-Glutamic acid & 0.93 \\
\hline & & & S-(5'Adenosyn)-L-Methionine & 0.96 \\
\hline & & & Spermidine & 1,39 \\
\hline & & & Fumarate & 1,15 \\
\hline & & & Creatine phosphate & 1.87 \\
\hline & & & Spermine & 2,20 \\
\hline
\end{tabular}

$361 \times 270 \mathrm{~mm}(300 \times 300 \mathrm{DPI})$ 
Page 3 of 45

Synapse

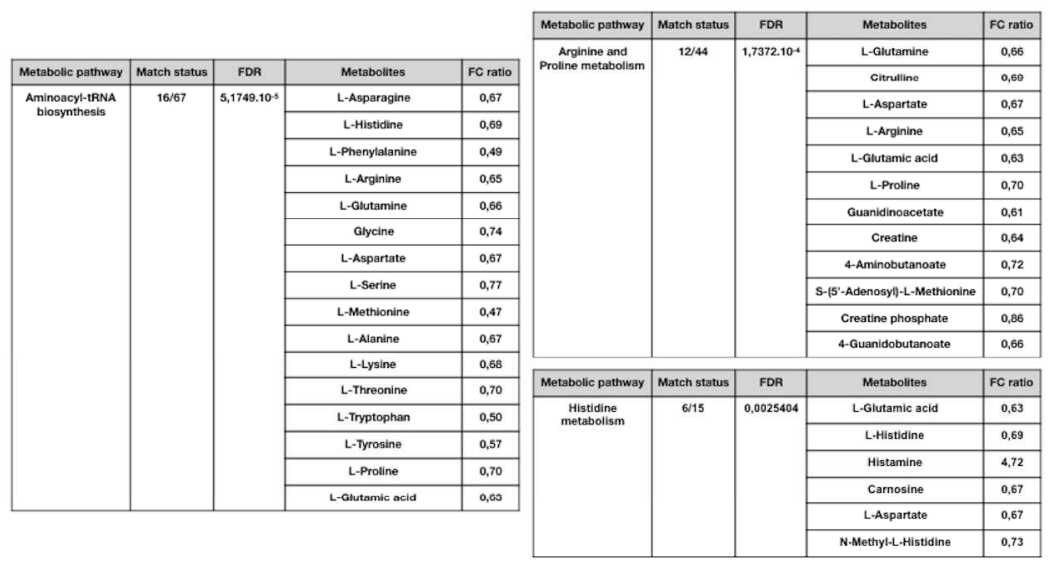

$361 \times 270 \mathrm{~mm}(300 \times 300$ DPI $)$ 


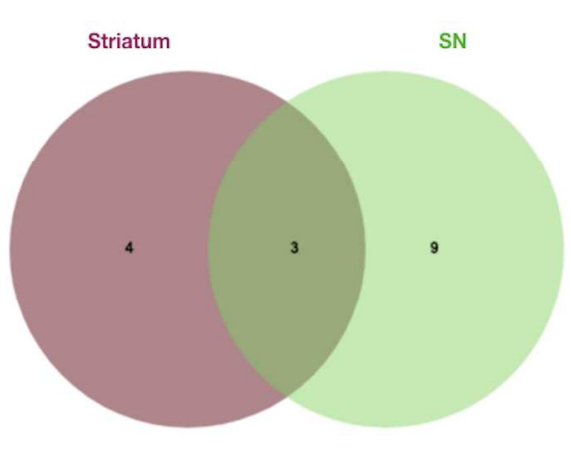

Elements only in Striatum (4):
L-Ornithine
Spermidine
Fumarate
Spermine
Elements only in SN (9) :
L-Glutamine
Gitrulline
L-Aspartate
L-Arginine
L-Proline
Guanidinoacetate
Greatine
4-Aminobutanoate
4-Guanidobutanoate
Common elements in Striatum and SN (3):
L-Glutamic acid
S-(5'-Adenosyl)-L-Methionine
Creatine pnospnate

$361 \times 270 \mathrm{~mm}(300 \times 300$ DPI $)$ 


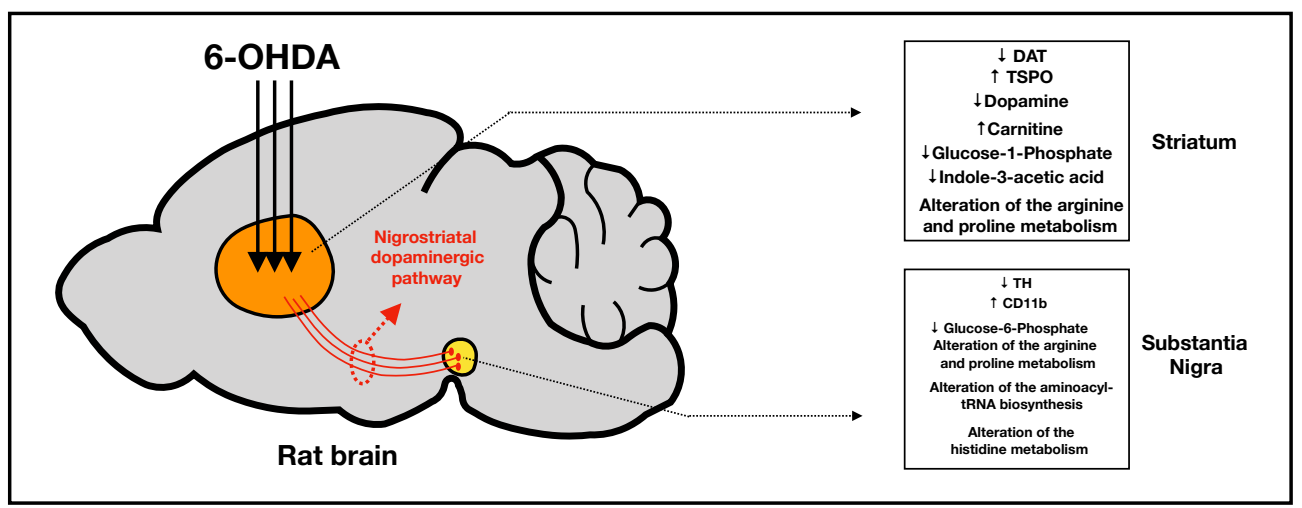


We performed multimodal explorations (PET imaging, autoradiography, immunohistochemistry, metabolomics) in a rat model reflecting early stages of Parkinson's disease.

We evidenced concomitant decrease of dopaminergic markers (dopamine transporter, tyrosine hydroxylase), increase in neuroinflammation markers (TSPO, CD11b) and alteration of specific metabolomics pathways (carnitine, arginine/proline, histidine) providing new insights in PD mechanisms and orientation towards new therapy. 
Extensive exploration of a novel rat model of Parkinson's disease using partial 6hydroxydopamine lesion of dopaminergic neurons suggests new therapeutic approaches

Steven Vetel ${ }^{1}$, Sophie Sérrière ${ }^{1}$, Johnny Vercouillie ${ }^{1,2}$, Jackie Vergote ${ }^{1}$, Gabrielle Chicheri $^{1}$, Jean-Bernard Deloye ${ }^{3}$, Frédéric Dollé ${ }^{4}$, Sylvie Bodard ${ }^{1}$, Claire Tronel $^{1}$, Lydie Nadal-Desbarats ${ }^{1}$, Antoine Lefèvre ${ }^{1}$, Patrick Emond ${ }^{1,5}$, Sylvie Chalon ${ }^{1 *}$

${ }^{1}$ UMR 1253, iBrain, Université de Tours, Inserm, Tours, France

${ }^{2}$ INSERM CIC 1415, University Hospital, Tours, France

${ }^{3}$ Zionexa, 42 avenue de la Grande Armée, 75017 Paris, France

${ }^{4}$ CEA, Institut des Sciences du Vivant Frédéric Joliot, Service hospitalier Frédéric

Joliot, Université Paris-Saclay, Orsay, France

${ }^{5}$ CHRU Tours, France

*Corresponding author at: UMR Inserm U1253, UFR de Médecine, 10 Boulevard Tonnellé, 37032 Tours Cedex 01, France, e-mail: sylvie.chalon@univ-tours.fr

\section{Acknowledgements}

We thank the Laboratories Cyclopharma for providing fluor-18 and Julie Busson for technical assistance. This manuscript was edited by an English-speaking scientist. This work was supported by the European Union's Seventh Framework Program (FP7/2007-2013) under grant agreement n²78850 (INMiND), by Labex IRON (ANR-11-LABX-18-01) and by Inserm. 


\section{Abstract}

Parkinson's disease (PD) is characterized by the degeneration of dopaminergic (DA) neurons constituting the nigrostriatal pathway. Neuroinflammation, related to microglial activation, plays an important role in this process. Exploration of animal models of PD using neuroimaging modalities allows to better understand the pathophysiology of the disease. Here, we fully explored a moderate lesion model in the rat in which 6-hydroxydopamine was unilaterally delivered in 3 sites along the striatum. The degenerative process was assessed through in vivo Positron Emission Tomography (PET) imaging and in vitro autoradiographic quantitation of the striatal dopamine transporter (DAT) and immunostaining of tyrosine hydroxylase (TH). The microglial activation was studied through in vitro autoradiographic quantitation of the $18 \mathrm{kDa}$ translocator protein (TSPO) in the striatum and CD11b staining in the SN. In addition, a targeted metabolomics exploration was performed in both these structures using mass spectrometry coupled to HPLC. Our results showed a reproducible decrease in the striatal DAT density associated with a reduction in the number of THpositive cells in the $\mathrm{SN}$ and striatum, reflecting a robust moderate degeneration of nigrostriatal DA neurons. In addition, we observed strong microglia activation in both the striatum and $\mathrm{SN}$ ipsilateral to the lesion, highlighting that this moderate degeneration of DA neurons was associated with a marked neuroinflammation. Our metabolomics studies revealed alterations of specific metabolites and metabolic pathways such as carnitine, arginine/proline and histidine metabolisms. These results bring new insights in the PD mechanism knowledge and new potential targets for future therapeutic strategies.

Key words: Neuroinflammation; PET imaging; metabolomics; dopamine transporter; TSPO 


\section{INTRODUCTION}

Parkinson's Disease (PD) is the second most common neurodegenerative disorder after Alzheimer's disease and affects approximately 4.5 million people worldwide, with that number estimated to double by 2030 (Nasrallah and Dubroff 2013). PD is mainly characterized by the gradual loss of dopaminergic (DA) neurons in the substantia nigra pars compacta (SNpc), leading to dopamine depletion in the striatum. These neurons constitute the nigrostriatal DA pathway which plays an essential role in the control of voluntary motor movement (Chinta and Andersen 2005). While 5\% of PD cases are inherited, 95\% have no apparent genetic etiology (referred to as “sporadic PD”) (Dauer and Przedborski 2003). Patients suffering from PD exhibit motor features that can be grouped under the acronym TRAP: Tremor at rest, Rigidity, Akinesia, and Postural instability (Jankovic 2008). Nowadays, it is widely accepted that PD is also characterized by non-motor symptoms such as sensory abnormalities, behavioral changes, sleep disturbances, and autonomic dysfunction (Pfeiffer 2016). Although several risks factors have been identified such as aging and long-term exposition to pesticides, the processes that lead to the loss of DA neurons are not yet fully understood. Many post-mortem brain imaging and fluid biomarker studies indicate that neuroinflammation is an important feature of PD (Poewe et al. 2017). Neuroinflammation is mainly characterized by microglial activation which induces the release of a large group of pro-inflammatory cytokines including tumor necrosis factor- $\alpha$ (TNF- $\alpha)$ and interleukin-1 $\beta$ (IL-1 $\beta$ ) that contribute to the degeneration of DA neurons (Wang et al. 2015). Moreover, DA neurons in the SNpc are particularly susceptible to microglial-mediated neurotoxicity due to the high density of microglia in this brain area (Collins et al. 2012). Consequently, targeting 
neuroinflammation constitutes a promising therapeutic strategy for PD.

Although all facets of PD are nearly impossible to model in animals (Vingill et al. 2017), these models are invaluable tools to gain knowledge of mechanisms involved in the pathological process and to evaluate new therapeutic approaches. In this context, the recent development of non-invasive imaging methods in small animals gives the unique opportunity to follow at the same time a number of various parameters such as brain activity, neurotransmission and neuroinflammation during the course of the disease, and the effects of potential treatments. In this field, positron emission tomography (PET) has already demonstrated its usefulness, particularly in 6hydroxydopamine (6-OHDA) lesion models of PD in rodents (Casteels et al. 2008; Fricke et al. 2016; Molinet-Dronda et al. 2015). Although these models have been well-recognized and widely used, most use direct injections of the toxin into the SNpc or medial forebrain bundle (MFB), producing a rapid and massive (>90\%) degeneration of DA neurons (Gubellini and Kachidian 2015) that reflect late stages of PD (Glajch et al. 2012). By contrast, administration of 6-OHDA in the striatum produces a progressive and moderate lesion corresponding to early stages of the disease (Kirik et al. 1998; Deumens et al. 2002), appearing therefore better adapted for the evaluation of potential treatments. Several modalities of striatal 6-OHDA administration have already been described, using different doses and injection sites. The administration of low dose in 3 different sites of the rat striatum was recently shown to induce a stable and reliable moderate lesion as assessed by rotational behavior and number of intact dopaminergic cells (Penttinen et al. 2016).

In this study, we fully characterized a close moderate 6-OHDA lesion model suitable 
for neuroimaging modalities, especially using PET. To this aim, we explored the degeneration of DA neurons by in vivo PET imaging with $\left[{ }^{18} \mathrm{~F}\right] \mathrm{LBT}-999$, a dopamine transporter (DAT) tracer useful for PET human studies (Arlicot et al. 2017; Ribeiro et al. 2017). These imaging findings were compared to other characteristics of the model, such as the microglia activation and brain metabolome which were explored through in vitro analyses.

\section{MATERIALS AND METHODS}

\subsection{Animals}

All procedures were conducted in accordance with the European Community Council Directive 2010/63/EU for laboratory animal care and the experimental procedure was validated by the Regional Ethical Committee (Authorization $\mathrm{N}^{\circ}$ 00434.02). Experiments were carried out on adult male Wistar rats (Charles River, France) weighting $300 \pm 5 \mathrm{~g}(\mathrm{n}=22)$ at the beginning of the experiments. Animals were housed in groups of two per cage in a temperature $\left(21 \pm 1^{\circ} \mathrm{C}\right)$ and humidity $(55 \pm 5 \%)$ controlled environment under a 12-h light/dark cycle, with food and water available ad libitum.

\subsection{6-OHDA lesion}

Twenty minutes before surgery, rats were injected intra-peritoneally with pargyline hydrochloride (50 mg/kg, Abcam, Paris, France) in order to prevent 6-OHDA oxidation by monoamine oxidase. Then, they were anesthetized with isoflurane (4\%, $500 \mathrm{~mL} / \mathrm{min}$, Baxter, France), placed on a stereotaxic frame (Stoelting, Phymep, Paris, France) and maintained under isoflurane $2.5 \%(500 \mathrm{~mL} / \mathrm{min})$ during surgery. Body temperature was monitored and kept as constant as possible $\left(37^{\circ} \mathrm{C}\right)$ using a 
thermal probe. Lesion was obtained by intrastriatal injection of 6-OHDA hydrochloride (Sigma-Aldrich, Saint-Quentin Fallavier, France). A total of $12 \mu \mathrm{g}$ of 6-OHDA was administered in three areas of the right striatum $(2 \mathrm{mg} / \mathrm{mL}$ in $0.01 \%$ ascorbic acid dissolved in saline, $\mathrm{pH} 4.5$, i.e. $4 \mu \mathrm{g}$ in $2 \mu \mathrm{L}$ for each area) using a $25 \mu \mathrm{L}$ Hamilton Gastight syringe (Hamilton, Massy, France) with a 30-gauge needle (Phymep, Paris, France). Stereotaxic coordinates from Bregma (Figure 1) were: AP1 $=+1.6 \mathrm{~mm}, \mathrm{~L} 1=-2.8 \mathrm{~mm}, \mathrm{P} 1=-6 \mathrm{~mm} ; \mathrm{AP} 2=0.0 \mathrm{~mm}, \mathrm{~L} 2=-4.1 \mathrm{~mm}, \mathrm{P} 2=-5.5 \mathrm{~mm}$; AP3 $=-1.2 \mathrm{~mm}, \mathrm{~L} 3=-4.5 \mathrm{~mm}, \mathrm{P} 3=-5.5 \mathrm{~mm}$, according to the rat brain Atlas of Paxinos and Watson (2009). The 6-OHDA solution was perfused at the rate of 0.5 $\mu \mathrm{L} / \mathrm{min}$. After each injection, the needle was kept in place for 5 minutes to minimize backflow of the solution. Following surgery, the rats were given buprenorphine $(0.05$ $\mathrm{mg} / \mathrm{kg}$ sub-cutaneously) for post-operative pain.

\subsection{Amphetamine-induced rotations test}

At 13 days post-lesion, all rats received an intra-peritoneal injection of damphetamine sulfate (3 mg/kg) (Sigma-Aldrich, Saint-Quentin Fallavier, France) and were placed in automatic rotometer bowls (Imetronic, Pessac, France). Fifteen minutes after injection, the number of ipsilateral rotation was measured for 2 hours. Full rotation was determined as a complete, uninterrupted $360^{\circ}$ turn.

\subsection{PET imaging study}

\subsubsection{Radiotracer preparation}

No-carrier added $\left[{ }^{18} \mathrm{~F}\right]$ LBT-999 was prepared as previously described (Sérrière et al. 2014) and obtained with a radiochemical purity $>98 \%$ and a specific activity comprised between 30 and $190 \mathrm{GBq} / \mu \mathrm{mol}$. 


\subsubsection{PET imaging and data analyses}

PET imaging was performed at 14 days post-lesion $(\mathrm{n}=8)$ using a microPET/CT SuperArgus system (Sedecal, Madrid, Spain), according to a previously published method (Sérrière et al. 2014). Before PET acquisition, a 5-minute computed tomography scan was acquired for attenuation correction. A bolus injection of 37 $\mathrm{MBq} / 300 \mathrm{~g}$ body weight of $\left[{ }^{18} \mathrm{~F}\right] \mathrm{LBT}-999$ in saline was administered into the tail vein of anesthetized rats, and acquisition lasted 50 min. PET images were analyzed with the region of interests (ROIs) for the left striatum (Contralateral-Striatum (C-ST), i.e non lesioned striatum), right striatum (Ipsilateral-Striatum (I-ST), i.e lesioned striatum), and Cerebellum (CE). In this study, the Standard Uptake Value ratio (SUVr) was used as quantitative criterion. All SUVrs were calculated using the CE as reference region.

\subsection{Metabolomics study}

\subsubsection{Brain tissue preparation}

After PET imaging, at 14 days post-lesion, animals $(n=8)$ were killed by decapitation and the following four ROIs were removed: C-ST, I-ST, contralateral-substantia nigra (C-SN), and ipsilateral-substantia nigra (I-SN). As previously described by Diémé et al. (2017), samples were weighted and lyophilized for 48 hours in a FreeZone ${ }^{\circledR}$ Freeze Dry Systems 4.5 I Benchtop lyophilizer (Labcono ${ }^{\circledR}$, Kansas City, Mo, USA) and milled to a fine powder (from $40 \mathrm{mg}$ of fresh tissue for striatum and $6 \mathrm{mg}$ for $\mathrm{SN}$, around $10 \mathrm{mg}$ and $1 \mathrm{mg}$ of powder were obtained for each structure, respectively). For the striatum, $3 \mathrm{mg}$ of each lyophilized sample was weighed for further extraction while for the SN, the entire lyophilized-tissue was extracted. After lyophilization, 
samples were extracted twice with $1.5 \mathrm{~mL}$ of acetonitrile/milliQ water (1/1). After centrifugation liquid phases were isolated and evaporated. Dried residues were kept at $-80^{\circ} \mathrm{C}$ before liquid chromatography-high resolution mass spectrometry (LC-HRMS) analysis.

\subsubsection{LC-HRMS analysis}

The dried residues were reconstituted in $150 \mu \mathrm{L} \mathrm{MeOH} / \mathrm{H}_{2} \mathrm{O}(1 / 1)$. As previously described by Diémé et al. (2017), LC-HRMS analysis was performed using a UPLC Ultimate 3000 system (Dionex, Sunnyvale, Calif., USA), coupled to a Q-Exactive mass spectrometer (Thermo Fisher Scientific, Germany) and operating in positive $(\mathrm{ESI}+)$ and negative (ESI-) electrospray ionization modes. Chromatography was carried out with a Phenomenex Kinetex $1.7 \mu \mathrm{m}$ XB-C18 $(150 \mathrm{~mm} \times 2.10 \mathrm{~mm})$ and $100 \AA$ A UHPLC column. Mobile phase A consisted of $0.1 \%$ formic acid in water and mobile phase B consisted of $0.1 \%$ formic acid in methanol. The gradient operated at a flow rate of $0.4 \mathrm{~mL} / \mathrm{min}$ over a run time of $30 \mathrm{~min}$. During the full-scan acquisition, which ranged from 60 to $900 \mathrm{~m} / \mathrm{z}$, the instrument operated at 70000 resolution $(\mathrm{m} / \mathrm{z}=$ 200). In order to equilibrate the chromatographic system, twenty quality controls (QCs) (obtained by mixing an equal volume of all samples) were injected. The sequence of samples for analysis was randomized and QCs were analyzed every 10 samples and at the end of the run. Data quality was checked based on QCs results by principal component analysis PCA.

\subsubsection{Targeted data processing}

A library of standard compounds (Mass Spectroscopy Metabolite Library of standards MS ML®, IROA technologies) was analysed with the same gradient of mobile phases 
and in the same conditions as those used to analyse our samples. The annotation of selected features was validated from retention time, and high resolution mass molecular (m/z) (Madji Hounoum et al. 2017). Targeted molecules were selected and integrated using Xcalibur 2.2 (Thermo Fisher Scientific, San Jose, CA). Each peak area was normalized to the dried mass of tissues. Coefficients of variation (CV) for QC samples were calculated. Only metabolites with high biological variability were selected and only metabolites with $\mathrm{CV}<30 \%$ in the QCs and $\mathrm{CV}>30 \%$ in the case where the biological variability (CV in samples) exceeded the analytical variability (CV in QCs).

\subsection{Autoradiographic and immunofluorescence analysis}

\subsubsection{Brain tissue preparation}

At 14 days post-lesion, rats $(n=14)$ were injected intra-peritoneally with an overdose of pentobarbital (60 mg/kg, Ceva Santé Animale, France) and transcardially perfused with cold sterile physiological water $(250 \mathrm{~mL}$ per rat). The brain was then carefully removed, frozen at $-35^{\circ} \mathrm{C}$ in an isopentane/dry ice mixture and stored at $-80^{\circ} \mathrm{C}$. Coronal brain sections (16- $\mu \mathrm{m}$ thick) were cut with a cryostat (CM3050S, Leica, Germany) at $-20^{\circ} \mathrm{C}$, collected on gelatinized slides and stored at $-80^{\circ} \mathrm{C}$ until the experiments.

\subsubsection{Autoradiography}

Two ligands were used for autoradiographic experiments. The first one was $\left[{ }^{125} \mathrm{I}\right] \mathrm{PE} 2 \mathrm{I}$ to quantify the DAT and the second one was $\left[{ }^{3} \mathrm{H}\right] \mathrm{DPA}-714$ to quantify the $18 \mathrm{kDa}$ translocation protein (TSPO). $\left[{ }^{125} \mathrm{I}\right] \mathrm{PE} 2 \mathrm{I}$ was radiolabeled according to Chalon et al. (1999) and obtained with a specific activity of $95 \mathrm{TBq} / \mathrm{mmol}$. $\left[{ }^{3} \mathrm{H}\right] \mathrm{DPA}-714$ was 
prepared according to Damont et al. (2015) and obtained with a specific activity of 2.01 TBq/mmol. Six brain sections per animal were studied. Brain sections were allowed to equilibrate at room temperature (RT) for 3 hours and were incubated with $100 \mathrm{pmol} / \mathrm{L}\left[{ }^{125} \mathrm{I}\right] \mathrm{PE} 2 \mathrm{I}$ in phosphate buffer $\mathrm{pH} 7.4$ at RT for 90 minutes or with 1 nmol/L $\left[{ }^{3} \mathrm{H}\right] \mathrm{DPA}-714$ in Tris-HCl buffer $\mathrm{pH} 7.4$ at RT for 60 minutes. Nonspecific binding was assessed in the presence of $100 \mu \mathrm{mol} / \mathrm{L}$ cocaine chlorhydrate (Cooper Industrie, Melun, France) for $\left[{ }^{125} \mathrm{I}\right] \mathrm{PE} 2 \mathrm{I}$ and $1 \mu \mathrm{mol} / \mathrm{L}$ PK-11195 (Sigma-Aldrich, Saint-Quentin Fallavier, France) for $\left[{ }^{3} \mathrm{H}\right] \mathrm{DPA}-714$, respectively. Sections were washed twice in ice-cold buffer $\left(4^{\circ} \mathrm{C}\right)$ for 5 minutes, then briefly in sterile water at $4^{\circ} \mathrm{C}$ and dried overnight at RT. Dry sections were made conductive by an application of metal electric tape (3M, Euromedex, Strasbourg, France) on the free side and then placed in the gas chamber of the $\beta$-imager ${ }^{\mathrm{TM}} 2000$ (Biospace Lab, Paris, France). Acquisitions were collected for 4 hours. Two anatomical ROIs for striatum (C-ST and I-ST) were selected manually and identified using the rat brain Atlas of Paxinos and Watson (2009). Using the $\beta$-vision software (Biospace Lab, Paris, France), the level of bound radioactivity was directly determined by counting the number of $\gamma$-rays for $\left[{ }^{125} \mathrm{I}\right] \mathrm{PE} 2 \mathrm{I}$ or $\beta$-particles for $\left[{ }^{3} \mathrm{H}\right] \mathrm{DPA}-714$ emitted from the delineated areas. Radioactivity was quantitated using an image analyzer (M3-vision Biospace Instruments). The radioligand signal in ROIs was measured for each rat and expressed as counts per minute per square millimeter $\left(\mathrm{cpm} / \mathrm{mm}^{2}\right)$. Specific binding was determined by subtracting non-specific binding from the total binding.

\subsubsection{Immunofluorescence}

For immunostaining of tyrosine hydroxylase $(\mathrm{TH})$ in both the striatum and $\mathrm{SN}$ and microglia using $\mathrm{CD} 11 \mathrm{~b}$ in the $\mathrm{SN}$, brain sections were post-fixed (using PFA 4\%, 30 
minutes) and blocked (using 5\% normal goat serum, $0.3 \%$ Triton $100 \mathrm{X}$ in $0.1 \mathrm{M}$ PBS, 3 hours at RT). Then, sections were incubated with anti-TH (1/1000; Abcam ab112, Paris, France) or an anti-CD11b (1/500; Merck Millipore CBL1512, Saint-Quentin en Yvelines, France) primary antibody overnight at $4{ }^{\circ} \mathrm{C}$ followed by an incubation with a fluorescence-coupled secondary antibody for 1 hour at RT: either a goat anti-rabbit (Alexa 555; Abcam ab150086, Paris, France) or a goat anti-mouse (Alexa 488; Abcam ab150113) at a dilution of 1/500. Finally, nuclei were counterstained using 4'6-diamino-2-phenylindole (DAPI) (1/10000; Sigma-Aldrich D9542, Saint-Quentin Fallavier, France) and sections were mounted using a mounting medium for fluorescent staining (Abcam Ab103746, Paris, France). TH and CD11b labeling were visualized using a Leica DM5500 B fluorescence microscope (Germany) with an ORCA-R2 camera (Hamamatsu Photonics, Massy, France). Pictures were analyzed using ImageJ Software. For TH labeling in the striatum, the percentage of the area stained by TH was automatically measured in each ROI in both the C-ST and I-ST. In the $\mathrm{SN}$, the number of TH positive cells was manually counted in the C-SN and the ISN. For CD11b labeling, a ROI of SN was designed for each section in both C-SN and I-SN. In these ROIs, the percentage of the area stained by CD11b was automatically measured.

\subsection{Statistical analysis}

All results were expressed as mean \pm standard error mean (SEM). For PET imaging, autoradiographic and immunofluorescence analysis, comparisons between C-ST and I-ST, and between C-SN and I-SN were performed using the Wilcoxon test twotailed. Statistical analyses were carried out with the GraphPad Prism software version 6. For the metabolomics study, multivariate analysis was performed using the Simca- 
$\mathrm{P}^{+}-13$ software (Umetrics, Umea, Sweden). Non-parametric tests were performed using MetaboAnalyst (www.metaboanalyst.ca) in order to select significant metabolites. As we were in a multiple testing cases, a non-parametric test was performed with an adjusted p-value (set at 0.05 ) with a False Discovery Rate (FDR) adjusted procedure (based on the Benjamini-Hochberg adjustment). Criteria for metabolite selection for further data processing were: variable importance in projection (VIP) score in multivariate analysis $>0.5$, fold change (FC) ratio $<0.75$ or $>1.25$ and a $p$-value $<0.05$. These metabolites were introduced in pathways analysis module in Metaboanalyst based on the latest version of KEEG, given a metabolic pathway analysis (MetPA). Pathways of interest were those showing a p-value $<0.05$ from the pathway enrichment analysis.

\section{RESULTS}

\subsection{Amphetamine-induced rotations test}

The amphetamine-induced rotations test was performed at 13 days post-lesion. All animals $(n=22)$ displayed a turning behavior, with an average of $8.73 \pm 0.67$ ipsilateral rotations per minute, demonstrating the 6-OHDA lesion.

\subsection{PET imaging study}

PET imaging of DAT with $\left[{ }^{18}\right.$ F]LBT-999 $(\mathrm{n}=7,1$ rat was excluded due to an injection problem) was performed at 14 days post-lesion. PET brain static images obtained between 30 and 50 minutes post-injection (Figure $2 \mathrm{~A}$ ) revealed that the accumulation of $\left[{ }^{18}\right.$ F]LBT-999 was much lower in the I-ST compared to the C-ST. The time activity curves (Figure 2B) showed a rapid uptake of $\left[{ }^{18}\right.$ F LBT-999 in all the ROIs (C-ST, I-ST and CE) after intravenous bolus injection. In the CE, the uptake 
decreased rapidly and remained low and stable from 20 minutes post-injection. In contrast, the uptake (SUV) remained high and stable in the C-ST compared to the I$\mathrm{ST}$ at 50 minutes post-injection $(4.39 \pm 0.31$ vs. $1.47 \pm 0.18)$. Analysis of SUVr to the CE obtained between 30 and 50 minutes post-injection (Figure 2C) showed a statistically significant reduction in the I-ST compared to the C-ST $(1.69 \pm 0.21$ vs. $4.68 \pm 0.38, p<0.05)$. In all, the SUVr in the I-ST was $64.46 \pm 1.68 \%$ lower than the SUVr in the C-ST, reflecting the intensity of the lesion.

\subsection{Metabolomics study}

Analyses of the metabolome of the striatum and SN were performed by LC-HRMS targeted analysis. The score plots resulting from the OPLS-DA for the striatum $(\mathrm{n}=$ 8) and the PLS-DA for the SN ( $n=7,1$ sample was inoperable because of extraction problem) are represented in Figure 3A and 3B, respectively. Each model was defined by a descriptive value $\left(\mathrm{R}^{2} \mathrm{Y}=\right.$ robustness of the model $)$ and a predictive value $\left(\mathrm{Q}^{2}=\right.$ predictive capacity of the model). $\mathrm{R}^{2} \mathrm{Y}$ was high for both the striatum and SN (0.90 and 0.84 , respectively) but $\mathrm{Q}^{2}$ was lower for the $\mathrm{SN}$ than for the striatum $(0.53$ and 0.78 , respectively). However, a $\mathrm{Q}^{2} \geq 0.4$ was considered as acceptable for a biological model (Worley and Powers 2013). Both OPLS-DA and PLS-DA showed a clear separation between the cerebral structures originating from the ipsilateral and contralateral hemispheres (I-ST vs C-ST and I-SN vs C-SN). Multivariate and univariate analysis (Table 1) identified several metabolites based on their VIP score (VIP score $>0.5)$, FC ratio $(0.75<\mathrm{FC}$ ratio $>1.25)$ and $p$-value $(p<0.05)$. For the striatum, 4 metabolites were identified: dopamine (lower in I-ST vs. C-ST), glucose1-phosphate (lower in I-ST vs. C-ST), L-carnitine (higher in I-ST vs. C-ST), and indole-3-acetic-acid (lower in I-ST vs. C-ST). For the SN, only one metabolite was 
identified: glucose-6-phosphate (lower in I-SN vs. C-SN). The metabolite pathway analysis showed a highly significant alteration of the arginine and proline metabolism both in the striatum and SN (supplementary Table $1 \&$ Table 2). The Venn diagram of this pathway highlighted specific alteration according to the brain structure (supplementary Figure 1). In addition, in the SN highly significant modifications were found in aminoacyl-tRNA biosynthesis and histidine metabolism (supplementary Table 2).

\subsection{Autoradiographic and immunofluorescence analysis}

The DAT density was evaluated on coronal brain sections by $\left[{ }^{125} \mathrm{I}\right] \mathrm{PE} 2 \mathrm{I}$ binding $(\mathrm{n}=$ 14) as illustrated in Figure 4A. As shown in Figure 4B, the specific binding of $\left[{ }^{125} \mathrm{I}\right] \mathrm{PE} 2 \mathrm{I}$ was significantly reduced in the I-ST compared to the C-ST $(4.66 \pm 0.33$ vs. $19.91 \pm 0.77 \mathrm{cpm} / \mathrm{mm}^{2}$, respectively, $\left.p=0.0001\right)$. The mean percentage of lesion was $76.35 \pm 1.71 \%$. The TSPO density was assessed by $\left[{ }^{3} \mathrm{H}\right] \mathrm{DPA}-714$ binding on adjacent brain sections from each animal as illustrated in Figure 4C. The specific binding of $\left[{ }^{3} \mathrm{H}\right] \mathrm{DPA}-714$ (Figure 4D) was significantly higher in the I-ST compared to the C-ST $\left(3.12 \pm 0.33\right.$ vs. $1.60 \pm 0.15 \mathrm{cpm} / \mathrm{mm}^{2}$, respectively, $\left.p=0.0001\right)$. The TSPO related to $\left[{ }^{3} \mathrm{H}\right] \mathrm{DPA}-714$ binding was $93.98 \pm 7.24 \%$ higher in the I-ST than in the C-ST.

The staining of TH was performed on coronal brain sections in both the C-ST and IST $(n=14)$ as illustrated in Figure 5A. Quantitative measurements in these ROIs (Figure 5B) showed that the area occupied by TH staining was significantly lower (by $71.26 \pm 2.34 \%)$ in the I-ST compared to the C-ST $(13.92 \pm 1.16$ vs. $48.45 \pm 0.43 \%$, respectively, $p=0.0001$ ). The staining of $\mathrm{TH}$ was also carried out on coronal brain sections in the SN $(n=14)$ (Figure 6A). Quantitative measurements in these ROIs 
(Figure 6B) showed that the number of TH-positive cells was statistically significantly lower (by $63.87 \pm 1.57 \%$ ) in the I-SN compared to the C-SN $(23.64 \pm$ 1.60 vs. $65.14 \pm 2.62 \mathrm{TH}$-positive cells, respectively, $p=0.0001)$. Immunostaining of $\mathrm{CD} 11 \mathrm{~b}$ was also performed (Figure 6C) on adjacent brain sections. As illustrated in Figure 6D, quantitative measurements showed that the area occupied by CD11b staining was statistically significantly higher (by $2690 \pm 330 \%$ ) in the I-SN compared to the C-SN (10.64 \pm 0.83 vs $0.44 \pm 0.04 \%$, respectively, $p=0.0001)$.

\section{DISCUSSION}

Since current PD treatments do not provide adequate neuroprotection and are unable to slow down the progression of $\mathrm{PD}$, there is an urgent need to reach novel therapeutic strategies (Tarazi et al. 2014). In this context, the development and characterization of animal models of PD enabling the evaluation of these treatments especially using neuroimaging modalities is paramount. Toxic models of PD are based on systemic or local administration of neurotoxins which induce degeneration of the nigrostriatal DA system (Blandini et al. 2008). Among these models, the injection of 6-OHDA (Ungerstedt 1968) in the striatum produces a specific retrograde, progressive, and moderate lesion of nigrostriatal DA neurons. This type of lesion mimicking early stages of PD appears more adapted than total lesions for the evaluation of potential neuroprotective strategies. However, the extension of the lesion depends on several experimental parameters including the total dose of injected toxin and the site of injection (Kirik et al. 1998). On this basis, we used a model in which the 6-OHDA is unilaterally delivered in 3 sites in the striatum, in order to achieve a moderate and stable lesion along the structure.

Our experiments were conducted at 14 days post-lesion, as it is known that the intra- 
striatal injection of 6-OHDA induces the degeneration of pre-synaptic nerve terminals within first days of injection, followed by a loss of dopaminergic cell bodies in the SN reaching a stable level from 2 weeks (Duty and Jenner 2011). We first assessed the rotational behavior of lesioned rats following amphetamine administration, which reflects the intensity of striatal dopamine depletion (Iancu et al. 2005; Tronci et al. 2012) and observed reproducible results among animals, indicative of a stable and reliable lesion. This observation was confirmed through direct in vivo evaluation of the striatal DAT using PET imaging, which provides assessment of dopaminergic nerve terminals (Brooks and Pavese 2011; Tatsch and Poepperl 2013). For this aim, we used the $\left[{ }^{18} \mathrm{~F}\right] \mathrm{LBT}-999$, a selective radioligand of DAT used as promising tracer in clinical research (Arlicot et al. 2017), which has proven its usefulness in 6-OHDAlesioned rats to quantitate the degree of lesion (Grealish et al. 2014; Serriere et al. 2015). Accumulation of $\left[{ }^{18} \mathrm{~F}\right] \mathrm{LBT}-999$ in the lesioned striatum was significantly lower than in the non-lesioned tissue, demonstrating a reproducible decrease in the DAT density reflecting the moderate (i.e., 70\%) intensity of the lesion. This finding was in agreement with the significant dopamine depletion that we measured in the ipsilateral striatum using LC-HRMS targeted analysis. The intensity of the lesion as measured by PET imaging in the striatum was similar to that we obtained both using autoradiographic experiments with the in vitro specific radioligand of DAT $\left[{ }^{125} \mathrm{I}\right] \mathrm{PE} 2 \mathrm{I}$ (Chalon et al. 1999) and using TH immunostaining. The ipsilateral SN showed a significant $(60 \%)$ and reproducible reduction in the number of TH-positive cells, reflecting a depletion of DA neurons cell bodies. Overall, these findings demonstrated that this model was characterized by a reproducible and moderate lesion of DA neurons that can be assessed by PET imaging.

In association with the loss of DA neurons, activation of CNS immune cells such as 
microglia is typically observed in animal models of PD and in the SN of PD patients both in PET scan and post-mortem studies (Thornton and Vink 2012). Microglial activation, one of the major hallmarks of neuroinflammation, induces the release of pro-inflammatory and cytotoxic molecules which contribute to DA neurons degeneration (Chao et al. 2014; Song and Kim 2016). At the same time, dying DA neurons release substances such as ATP which promote microglial activation (Saijo and Glass 2011). This bi-directional interaction between microglia and DA neurons is known to fuel the neurodegenerative process. In our model, we quantitated the striatal density of the $18 \mathrm{kDa}$ TSPO which is considered as a sensitive marker of microglial activation (Chen and Guilarte 2008; Rupprecht et al. 2010) using $\left[{ }^{3} \mathrm{H}\right] \mathrm{DPA}-714$, a highly sensitive radioligand of TSPO which has demonstrated its usefulness to assess striatal microglial activation in a rat model of brain excitotoxicity (Foucault-Fruchard et al. 2017). In parallel, microglial activation was assessed in the $\mathrm{SN}$ using immunostaining of CD11b, a surface protein which is overexpressed during activation of these cells (Roy et al. 2008). We observed robust microglial activation in both the striatum and SN ipsilateral to the lesion, indicating that the partial degeneration of nigrostriatal DA neurons was associated with marked neuroinflammation, in agreement with previously obtained data (Maia et al. 2012).

In order to better characterize the animal model, we performed a metabolomics analysis of brain structures involved in the nigrostriatal DA pathway, i.e., the striatum and SN. To our knowledge, only a few metabolomics studies have been performed in preclinical models of PD (Gao et al. 2013; Zheng et al. 2016). Dopamine depletion in the ipsilateral striatum was accompanied with a significant decrease in two metabolites associated with glucose pathways, glucose-1-phosphate in the ipsilateral striatum and glucose-6-phosphate in the ipsilateral SN. These results are in agreement 
with $\left[{ }^{18} \mathrm{~F}\right]$-FDG PET imaging studies performed in 6-OHDA models indicating an hypometabolism in the striatum and SN on the lesioned side (Casteels et al. 2008; Jang et al. 2012; Silva et al. 2013). Interestingly, we observed a significant increase in free carnitine in the ipsilateral striatum but not in the SN. This increase could be an endogenous mechanism aimed at protecting dopaminergic nerve endings. In this context, L-carnitine and its acetylated derivative acetyl-L-carnitine have been shown to have anti-inflammatory properties when used as supplement in different animal models of neurodegenerative disorders (Silva-Adaya et al. 2008; Sarkar et al. 2015; Afshin-Majd et al. 2017; Ferreira and McKenna 2017). It is widely supposed that brain did not use fatty acids as energy substrates (Panov et al. 2014; Schonfeld et al. 2013). However, although this is true for neurons, the carnitine palmitoyl transferase (CPT) system, which allows the entry of long-chain fatty acids into the mitochondria for ß-oxidation, is functional in astrocytes (Panov et al. 2014; Jernberg et al. 2017) and in embryonic (Xie et al. 2016) and adult (Knobloch et al. 2017) neural stem cells. The role of carnitine in its anti-inflammatory or energetic functions remains to be elucidated in this model and may constitute for the future a starting point for the development of innovative therapeutic.

Beside single significant metabolites, the arginine and proline pathway was found to be altered both in the striatum and $\mathrm{SN}$. Three metabolites involved in the polyamines biosynthesis were specifically modified in the striatum (L-Ornithine, Spermine and Spermidine). Polyamines are ubiquitous molecules involved in apoptosis, cell division and signal transduction (Handa et al. 2018) although its precise role remains to be elucidated. Accumulating evidences suggest that polyamines pathway is involved in the pathogenesis of PD (Gomes-Trolin et al. 2002; Lewandowski et al. 2010). In the $\mathrm{SN}$, a highly significant modification was found in aminoacyl-tRNA biosynthesis 
involving L-Phenylalanine and L-Tyrosine and in the histidine metabolism in agreement with the lesion. In this later pathway, an increased level of histamine was observed, as already reported PD subjects (Anichtchik et al. 2000; Rinne et al. 2002). It can be pointed out that histamine can have neurotoxic effect (Vizuete et al. 2000; Rocha et al. 2016; Liu et al. 2007). These results show that, alongside dopaminergic and energetic (glucose consumption) deregulation already known in PD, other alterations are observed (carnitine, polyamines, amino acids).

In conclusion, we extensively explored a robust 6-OHDA lesion model of PD in the rat which was characterized by a reproducible and moderate degeneration of DA neurons associated with a marked neuroinflammation, mimicking the early stages of the disease. The density of DA neurons was reliably quantitated in vivo by PET. Microglia activation was assessed herein using the TSPO ligand DPA-714, in vitro, but this ligand is also useful for clinical (Hamelin et al. 2016) and rat (Kong et al. 2016; Ory et al. 2016; Thomas et al. 2016) PET imaging.

Our original metabolomics studies highlighted the alteration of specific metabolites and metabolic pathways. It is not clear whether these modifications are deleterious or compensatory protective endogenous mechanisms consecutive to the lesion. In this context, further experiments will be necessary to evidence potential beneficial impact induced by the modulation of the carnitine, arginine/proline and/or histidine metabolism.

\section{REFERENCES}

- Afshin-Majd, S., Bashiri, K., Kiasalari, Z., Baluchnejadmojarad, T., Sedaghat, R., Roghani, M. 2017. Acetyl-1-carnitine protects dopaminergic nigrostriatal pathway in 
6-hydroxydopamine-induced model of Parkinson's disease in the rat. Biomed Pharmacother, 89: 1-9. DOI: 10.1016/j.biopha.2017.02.007.

- Anichtchik, O. V., Rinne, J. O., Kalimo, H., Panula, P. 2000. An altered histaminergic innervation of the substantia nigra in Parkinson's disease. Exp Neurol, 163: 20-30. DOI: 10.1006/exnr.2000.7362.

- Arlicot, N., Vercouillie, J., Malherbe, C., Bidault, R., Gissot, V., Maia, S., Barantin, L., Cottier, J. P., Deloye, J. B., Guilloteau, D., Ribeiro, M. J. 2017. PET imaging of Dopamine Transporter with 18F-LBT999: first human exploration. J Nucl Med, 58: 276.

- Blandini, F., Armentero, M. T., Martignoni, E. 2008. The 6-hydroxydopamine model: news from the past. Parkinsonism Relat Disor, 14 Suppl 2, S124-S129. DOI: 10.1016/j.parkreldis.2008.04.015.

- Brooks, D. J., Pavese, N. 2011. Imaging biomarkers in Parkinson's disease. Prog Neurobiol, 95: 614-628. DOI: 10.1016/j.pneurobio.2011.08.009.

- Casteels, C., Lauwers, E., Bormans, G., Baekelandt, V., Van Laere, K. 2008. Metabolic-dopaminergic mapping of the 6-hydroxydopamine rat model for Parkinson's disease. Eur J Nucl Med Mol Imaging, 35: 124-134. DOI: 10.1007/s00259-007-0558-3.

- Chalon, S., Garreau, L., Emond, P., Zimmer, L., Vilar, M. P., Besnard, J. C., Guilloteau, D. 1999. Pharmacological characterization of (E)-N-(3-iodoprop-2-enyl)$2 \beta$-carbomethoxy-3 $\beta$-(4'-methylphenyl)nortropane as a selective and potent inhibitor of the neuronal dopamine transporter. J Pharmacol Exp Ther, 291: 648-654.

- Chao, Y., Wong, S. C., Tan, E. K. 2014. Evidence of inflammatory system involvement in Parkinson's disease. Biomed Res Int, 2014: 308654. DOI: $10.1155 / 2014 / 308654$ 
- Chen, M. K., Guilarte, T. R. 2008. Translocator protein 18 kDa (TSPO): molecular sensor of brain injury and repair. Pharmacol Ther, 118: 1-17. DOI: 10.1016/j.pharmthera.2007.12.004.

- Chinta, S. J., Andersen, J. K. 2005. Dopaminergic neurons. Int J Biochem Cell Biol, 37: 942-946. DOI: 10.1016/j.biocel.2004.09.009.

- Collins, L. M., Toulouse, A., Connor, T. J., Nolan, Y. M. 2012. Contributions of central and systemic inflammation to the pathophysiology of Parkinson's disease. Neuropharmacology, 62: 2154-2168. DOI: 10.1016/j.neuropharm.2012.01.028.

- Damont, A., Garcia-Argote, S., Buisson, D. A., Rousseau, B., Dolle, F. 2015. Efficient tritiation of the translocator protein $(18 \mathrm{kDa})$ selective ligand DPA-714. $J$ Labelled Comp Radiopharm, 58: 1-6. DOI: 10.1002/jlcr.3252.

- Dauer, W., Przedborski, S. 2003. Parkinson's disease: mechanisms and models. Neuron, 39: 889-909.

- Deumens, R., Blokland, A., Prickaerts, J. 2002. Modeling Parkinson's disease in rats: an evaluation of 6-OHDA lesions of the nigrostriatal pathway. Exp Neurol, 175: 303-317. DOI: 10.1006/exnr.2002.7891.

- Diémé, B., Lefèvre, A., Nadal-Desbarats, L., Galineau, L., Madji Hounoum, B., Montigny, F., Blasco, H., Andres, C. R., Emond, P., Mavel, S. 2017. Workflow methodology for rat brain metabolome exploration using NMR, LC-MS and GC-MS analytical platforms. $J$ Pharm Biomed Anal, 142: 270-278. DOI: 10.1016/j.jpba.2017.03.068.

- Duty, S., Jenner, P. 2011. Animal models of Parkinson's disease: a source of novel treatments and clues to the cause of the disease. $\mathrm{Br} J$ Pharmacol, 164: 1357-1391. DOI: $10.1111 /$ j.1476-5381.2011.01426.x.

- Ferreira, G. C., McKenna, M. C. 2017. L-Carnitine and Acetyl-L-carnitine Roles 
and Neuroprotection in Developing Brain. Neurochem Res, 42: 1661-1675. DOI: 10.1007/s11064-017-2288-7.

- Foucault-Fruchard, L., Doméné, A., Page, G., Windsor, M., Emond, P., Rodrigues, N., Dolle, F., Damont, A., Buron, F., Routier, S., Chalon, S., Antier, D. 2017. Neuroprotective effect of the alpha 7 nicotinic receptor agonist PHA 543613 in an in vivo excitotoxic adult rat model. Neuroscience, 356: 52-63. DOI: 10.1016/j.neuroscience.2017.05.019.

- Fricke, I. B., Viel, T., Worlitzer, M. M., Collmann, F. M., Vrachimis, A., Faust, A., Wachsmuth, L., Faber, C., Dolle, F., Kuhlmann, M. T., Schafers, K., Hermann, S., Schwamborn, J. C., Jacobs, A. H. 2016. 6-hydroxydopamine-induced Parkinson's disease-like degeneration generates acute microgliosis and astrogliosis in the nigrostriatal system but no bioluminescence imaging-detectable alteration in adult neurogenesis. Eur J Neurosci, 43: 1352-1365. DOI: 10.1111/ejn.13232.

- Gao, H. C., Zhu, H., Song, C. Y., Lin, L., Xiang, Y., Yan, Z. H., Bai, G. H., Ye, F. Q., Li, X. K. 2013. Metabolic changes detected by ex vivo high resolution 1H NMR spectroscopy in the striatum of 6-OHDA-induced Parkinson's rat. Mol Neurobio, 47: 123-130. DOI: 10.1007/s12035-012-8336-z.

- Glajch, K. E., Fleming, S. M., Surmeier, D. J., Osten, P. 2012. Sensorimotor assessment of the unilateral 6-hydroxydopamine mouse model of Parkinson's disease. Behav Brain Res, 230: 309-316. DOI: 10.1016/j.bbr.2011.12.007.

- Gomes-Trolin, C., Nygren, I., Aquilonius, S. M., Askmark, H. 2002. Increased red blood cell polyamines in ALS and Parkinson's disease. Exp Neurol, 177: 515-520.

- Grealish, S., Diguet, E., Kirkeby, A., Mattsson, B., Heuer, A., Bramoulle, Y., Van Camp, N., Perrier, A. L., Hantraye, P., Bjorklund, A., Parmar, M. 2014. Human ESCderived dopamine neurons show similar preclinical efficacy and potency to fetal 
neurons when grafted in a rat model of Parkinson's disease. Cell Stem Cell, 15: 653665. DOI: 10.1016/j.stem.2014.09.017.

- Gubellini, P., Kachidian, P. 2015. Animal models of Parkinson's disease: An updated overview. Rev Neurol (Paris), 171: 750-761. DOI: 10.1016/j.neurol.2015.07.011.

- Hamelin, L., Lagarde, J., Dorothee, G., Leroy, C., Labit, M., Comley, R. A., de Souza, L. C., Corne, H., Dauphinot, L., Bertoux, M., Dubois, B., Gervais, P., Colliot, O., Potier, M. C., Bottlaender, M., Sarazin, M. IMABio team Clinical. 2016. Early and protective microglial activation in Alzheimer's disease: a prospective study using 18F-DPA-714 PET imaging. Brain, 139: 1252-1264. DOI: 10.1093/brain/aww017.

- Handa, A. K., Fatima, T., Mattoo, A. K. 2018. Polyamines: Bio-Molecules with Diverse Functions in Plant and Human Health and Disease. Front Chem, 6: 10. DOI: 10.3389/fchem.2018.00010.

- Iancu, R., Mohapel, P., Brundin, P., Paul, G. 2005. Behavioral characterization of a unilateral 6-OHDA-lesion model of Parkinson's disease in mice. Behav Brain Res, 162: 1-10. DOI: 10.1016/j.bbr.2005.02.023.

- Jang, D. P., Min, H. K., Lee, S. Y., Kim, I. Y., Park, H. W., Im, Y. H., Lee, S., Sim, J., Kim, Y. B., Paek, S. H., Cho, Z. H. 2012. Functional neuroimaging of the 6OHDA lesion rat model of Parkinson's disease. Neurosci Lett, 513: 187-192. DOI: 10.1016/j.neulet.2012.02.034.

- Jankovic, J. 2008. Parkinson's disease: clinical features and diagnosis. J Neurol Neurosurg. Psychiatry, 79: 368-376. DOI: 10.1136/jnnp.2007.131045.

- Jernberg, J. N., Bowman, C. E., Wolfgang, M. J., Scafidi, S. 2017. Developmental regulation and localization of carnitine palmitoyltransferases (CPTs) in rat brain. $J$ Neurochem, 142: 407-419. DOI: 10.1111/jnc.14072. 
- Kirik, D., Rosenblad, C., Bjorklund, A. 1998. Characterization of behavioral and neurodegenerative changes following partial lesions of the nigrostriatal dopamine system induced by intrastriatal 6-hydroxydopamine in the rat. Exp Neurol, 152: 259277. DOI: 10.1006/exnr.1998.6848.

- Knobloch, M., Pilz, G. A., Ghesquiere, B., Kovacs, W. J., Wegleiter, T., Moore, D. L., Hruzova, M., Zamboni, N., Carmeliet, P., Jessberger, S. 2017. A Fatty Acid Oxidation-Dependent Metabolic Shift Regulates Adult Neural Stem Cell Activity. Cell Rep, 20: 2144-2155. DOI: 10.1016/j.celrep.2017.08.029.

- Kong, X., Luo, S., Wu, J. R., Wu, S., De Cecco, C. N., Schoepf, U. J., Spandorfer, A. J., Wang, C. Y., Tian, Y., Chen, H. J., Lu, G. M., Yang, G. F., Zhang, L. J. 2016. (18)F-DPA-714 PET Imaging for Detecting Neuroinflammation in Rats with Chronic Hepatic Encephalopathy. Theranostics, 6: 1220-1231. DOI: 10.7150/thno.15362.

- Lewandowski, N. M., Ju, S., Verbitsky, M., Ross, B., Geddie, M. L., Rockenstein, E., Adame, A., Muhammad, A., Vonsattel, J. P., Ringe, D., Cote, L., Lindquist, S., Masliah, E., Petsko, G. A., Marder, K., Clark, L. N., Small, S. A. 2010. Polyamine pathway contributes to the pathogenesis of Parkinson disease. Proc Natl Acad Sci US $A, 107:$ 16970-16975. DOI: 10.1073/pnas.1011751107.

- Liu, C. Q., Chen, Z., Liu, F. X., Hu, D. N., Luo, J. H. 2007. Involvement of brain endogenous histamine in the degeneration of dopaminergic neurons in 6hydroxydopamine-lesioned rats. Neuropharmacology, 53: 832-841. DOI: 10.1016/j.neuropharm.2007.08.014.

- Madji Hounoum, B., Mavel, S., Coque, E., Patin, F., Vourc'h, P., Marouillat, S., Nadal-Desbarats, L., Emond, P., Corcia, P., Andres, C. R., Raoul, C., Blasco, H. 2017. Wildtype motoneurons, ALS-Linked SOD1 mutation and glutamate profoundly modify astrocyte metabolism and lactate shuttling. Glia, 65: 592-605. DOI: 
10.1002/glia.23114.

- Maia, S., Arlicot, N., Vierron, E., Bodard, S., Vergote, J., Guilloteau, D., Chalon, S. 2012. Longitudinal and parallel monitoring of neuroinflammation and neurodegeneration in a 6-hydroxydopamine rat model of Parkinson's disease. Synapse, 66: 573-583. DOI: 10.1002/syn.21543.

- Molinet-Dronda, F., Gago, B., Quiroga-Varela, A., Juri, C., Collantes, M., Delgado, M., Prieto, E., Ecay, M., Iglesias, E., Marin, C., Penuelas, I., Obeso, J. A. 2015. Monoaminergic PET imaging and histopathological correlation in unilateral and bilateral 6-hydroxydopamine lesioned rat models of Parkinson's disease: a longitudinal in-vivo study. Neurobiol Dis, 77: 165-172. DOI: 10.1016/j.nbd.2015.01.007.

- Nasrallah, I., Dubroff, J. 2013. An overview of PET neuroimaging. Semin Nucl Med, 43: 449-461. DOI: 10.1053/j.semnuclmed.2013.06.003.

- Ory, D., Postnov, A., Koole, M., Celen, S., de Laat, B., Verbruggen, A., Van Laere, K., Bormans, G., Casteels, C. 2016. Quantification of TSPO overexpression in a rat model of local neuroinflammation induced by intracerebral injection of LPS by the use of [(18)F]DPA-714 PET. Eur J Nucl Med Mol Imaging, 43: 163-172. DOI: $10.1007 / \mathrm{s} 00259-015-3172-9$.

- Panov, A., Orynbayeva, Z., Vavilin, V., Lyakhovich, V. 2014. Fatty acids in energy metabolism of the central nervous system. Biomed Res Int, 2014: 472459. DOI: $10.1155 / 2014 / 472459$.

- Paxinos, G., Watson, C. 2009. The Rat Brain in Stereotaxic coordinates. Elsevier Academic Press, San Diego.

- Penttinen, A. M., Suleymanova, I., Albert, K., Anttila, J., Voutilainen, M. H., Airavaara, M. 2016. Characterization of a new low-dose 6-hydroxydopamine model 
of Parkinson's disease in rat. J Neurosci Res, 94: 318-328. DOI: 10.1002/jnr.23708.

- Pfeiffer, R. F. 2016. Non-motor symptoms in Parkinson's disease. Parkinsonism Relat Disord, 22 Suppl 1, S119-S122. DOI: 10.1016/j.parkreldis.2015.09.004.

- Poewe, W., Seppi, K., Tanner, C. M., Halliday, G. M., Brundin, P., Volkmann, J., Schrag, A. E., Lang, A. E. 2017. Parkinson disease. Nat Rev Dis Primers, 3: 17013. DOI: $10.1038 / \operatorname{nrdp} .2017 .13$.

- Ribeiro, M. J., Vercouillie, J., Arlicot, N., Mondon, K., Gissot, V., Maia, S., Barantin, L., Cottier, J. P., Deloye, J. B., Guilloteau, D. 2017. A simplified method for the diagnosis of striatal dopaminergic dysfunction using PET with a new fluorine DAT tracer, the 18F-LBT-999. J Nucl Med, 58: 413.

- Rinne, J. O., Anichtchik, O. V., Eriksson, K. S., Kaslin, J., Tuomisto, L., Kalimo, H., Roytta, M., Panula, P. 2002. Increased brain histamine levels in Parkinson's disease but not in multiple system atrophy. J Neurochem, 81: 954-960.

- Rocha, S. M., Saraiva, T., Cristovao, A. C., Ferreira, R., Santos, T., Esteves, M., Saraiva, C., Je, G., Cortes, L., Valero, J., Alves, G., Klibanov, A., Kim, Y. S., Bernardino, L. 2016. Histamine induces microglia activation and dopaminergic neuronal toxicity via H1 receptor activation. J Neuroinflammation, 13: 137. DOI: 10.1186/s12974-016-0600-0.

- Roy, A., Jana, A., Yatish, K., Freidt, M. B., Fung, Y. K., Martinson, J. A., Pahan. K. 2008. Reactive oxygen species up-regulate CD11b in microglia via nitric oxide: Implications for neurodegenerative diseases. Free Radic Biol Med, 45: 686-699. DOI: 10.1016/j.freeradbiomed.2008.05.026.

- Rupprecht, R., Papadopoulos, V., Rammes, G., Baghai, T. C., Fan, J., Akula, N., Groyer, G., Adams, D., Schumacher, M. 2010. Translocator protein (18 kDa) (TSPO) as a therapeutic target for neurological and psychiatric disorders. Nat Rev Drug 
Discov, 9: 971-988. DOI: 10.1038/nrd3295.

- Saijo, K., Glass, C. K. 2011. Microglial cell origin and phenotypes in health and disease. Nat Rev Immunol, 11: 775-787. DOI: 10.1038/nri3086.

- Sarkar, S., Gough, B., Raymick, J., Beaudoin, M. A., Ali, S. F., Virmani, A., Binienda, Z. K. 2015. Histopathological and electrophysiological indices of rotenoneevoked dopaminergic toxicity: Neuroprotective effects of acetyl-L-carnitine. Neurosci Lett, 606: 53-59. DOI : 10.1016/j.neulet.2015.08.044.

- Schönfeld, P., Reiser, G. 2013. Why does brain metabolism not favor burning of fatty acids to provide energy? Reflections on disadvantages of the use of free fatty acids as fuel for brain. J Cereb Blood Flow Metab, 33: 1493-1499. DOI: 10.1038/jcbfm.2013.128.

- Sérrière, S., Tauber, C., Vercouillie, J., Guilloteau, D., Deloye, J. B., Garreau, L., Galineau, L., Chalon, S. 2014. In vivo PET quantification of the dopamine transporter in rat brain with [(1)(8)F]LBT-999. Nucl Med Biol, 41: 106-113. DOI: 10.1016/j.nucmedbio.2013.09.007.

- Sérrière, S., Doméné, A., Vercouillie, J., Mothes, C., Bodard, S., Rodrigues, N., Guilloteau, D., Routier, S., Page, G., Chalon, S. 2015. Assessment of the Protection of Dopaminergic Neurons by an alpha7 Nicotinic Receptor Agonist, PHA 543613 Using [(18)F]LBT-999 in a Parkinson's Disease Rat Model. Front Med (Lausanne), 2: 61. DOI: $10.3389 /$ fmed.2015.00061.

- Silva, M. D., Glaus, C., Hesterman, J. Y., Hoppin, J., Puppa, G. H., Kazules, T., Orcutt, K. M., Germino, M., Immke, D., Miller, S. 2013. Regional, kinetic [(18)F]FDG PET imaging of a unilateral Parkinsonian animal model. Am J Nucl Med Mol Imaging, 3: 129-141.

- Silva-Adaya, D., Perez-De La Cruz, V., Herrera-Mundo, M. N., Mendoza-Macedo, 
K., Villeda-Hernandez, J., Binienda, Z., Ali, S. F., Santamaria, A. 2008. Excitotoxic damage, disrupted energy metabolism, and oxidative stress in the rat brain: antioxidant and neuroprotective effects of L-carnitine. J Neurochem, 105: 677-689. DOI: $10.1111 /$ j.1471-4159.2007.05174.x.

- Song, J., Kim, J. 2016. Degeneration of Dopaminergic Neurons Due to Metabolic Alterations and Parkinson's Disease. Front Aging Neurosci, 8: 65. DOI: 10.3389/fnagi.2016.00065.

- Tarazi, F. I., Sahli, Z. T., Wolny, M., Mousa, S. A. 2014. Emerging therapies for Parkinson's disease: from bench to bedside. Pharmacol Ther, 144: 123-133. DOI: 10.1016/j.pharmthera.2014.05.010.

- Tatsch, K., Poepperl, G. 2013. Nigrostriatal dopamine terminal imaging with dopamine transporter SPECT: an update. J Nucl Med, 54: 1331-1338. DOI: 10.2967/jnumed.112.105379.

- Thomas, C., Vercouillie, J., Doméné, A., Tauber, C., Kassiou, M., Guilloteau, D., Destrieux, C., Sérrière, S., Chalon, S. 2016. Detection of Neuroinflammation in a Rat Model of Subarachnoid Hemorrhage Using [18F]DPA-714 PET Imaging. Mol Imaging, 15. DOI: 10.1177/1536012116639189.

- Thornton, E., Vink, R. 2012. Treatment with a substance P receptor antagonist is neuroprotective in the intrastriatal 6-hydroxydopamine model of early Parkinson's disease. PLoS One 7, e34138. DOI: 10.1371/journal.pone.0034138.

- Tronci, E., Shin, E., Bjorklund, A., Carta, M. 2012. Amphetamine-induced rotation and L-DOPA-induced dyskinesia in the rat 6-OHDA model: a correlation study. Neurosci Res, 73: 168-172. DOI: 10.1016/j.neures.2012.03.004.

- Ungerstedt, U. 1968. 6-Hydroxy-dopamine induced degeneration of central monoamine neurons. Eur J Pharmacol, 5: 107-110. 
- Vingill, S., Connor-Robson, N., Wade-Martins, R. 2017. Are rodent models of Parkinson's disease behaving as they should?. Behav Brain Res. DOI: 10.1016/j.bbr.2017.10.021.

- Vizuete, M. L., Merino, M., Venero, J. L., Santiago, M., Cano, J., Machado, A. 2000. Histamine infusion induces a selective dopaminergic neuronal death along with an inflammatory reaction in rat substantia nigra. J Neurochem, 75: 540-552.

- Wang, Q., Liu, Y., Zhou, J. 2015. Neuroinflammation in Parkinson's disease and its potential as therapeutic target. Transl Neurodegener, 4: 19. DOI: 10.1186/s40035015-0042-0.

- Worley, B., Powers, R. 2013. Multivariate Analysis in Metabolomics. Curr Metabolomics, 1: 92-107. DOI: 10.2174/2213235X11301010092.

- Xie, Z., Jones, A., Deeney, J. T., Hur, S. K., Bankaitis, V. A. 2016. Inborn Errors of Long-Chain Fatty Acid beta-Oxidation Link Neural Stem Cell Self-Renewal to Autism. Cell Rep, 14: 991-999. DOI: 10.1016/j.celrep.2016.01.004.

- Zheng, H., Zhao, L., Xia, H., Xu, C., Wang, D., Liu, K., Lin, L., Li, X., Yan, Z., Gao, H. 2016. NMR-Based Metabolomics Reveal a Recovery from Metabolic Changes in the Striatum of 6-OHDA-Induced Rats Treated with Basic Fibroblast Growth Factor. Mol Neurobiol, 53: 6690-6697. DOI: 10.1007/s12035-015-9579-2. 
Table 1. Metabolites identified by multivariate and univariate analysis in the striatum and SN with VIP score $>0.50,0.75<\mathrm{FC}$ ratio $>1.25$ and a $p$-value $<$ 0.05. Abbreviations: SN (Substantia Nigra), C-ST (Contralateral-Striatum), I-ST (Ipsilateral-Striatum), C-SN (Contralateral-Substantia Nigra), I-SN (IpsilateralSubstantia Nigra).

\begin{tabular}{|c|c|c|c|}
\hline Metabolite & VIP score & FC ratio & $p$-value \\
\hline \multicolumn{4}{|c|}{ Striatum } \\
\hline Dopamine & 2.37 & 0.44 & 0.002 \\
\hline Glucose-1-phosphate & 0.53 & 0.58 & 0.038 \\
\hline L-Carnitine & 1.91 & 1.32 & 0.001 \\
\hline Indole-3-acetic acid & 2.28 & 0.56 & 0.007 \\
\hline \multicolumn{4}{|c|}{ SN } \\
\hline Glucose-6-phosphate & 0.93 & 0.57 & 0.037 \\
\hline
\end{tabular}




\section{FIGURE LEGENDS}

Figure 1. Stereotaxic coordinates of 6-OHDA injection in the right striatum (delimited by a red line) according to the rat brain Atlas of Paxinos and Watson (2009). Abbreviation: 6-OHDA (6-hydroxydopamine).

Figure 2. PET imaging study: quantification of DAT with $\left[{ }^{18} \mathrm{~F}\right] \mathrm{LBT}-999$ in 6-OHDAlesioned rats $(\mathrm{n}=7)$. PET brain static axial image (upper side) and coronal image (lower side) with $\left[{ }^{18}\right.$ F]LBT-999 co-registered with the MRI-template (A). Mean timeactivity curves of $\left[{ }^{18} \mathrm{~F}\right] \mathrm{LBT}-999 \mathrm{SUVs}$ in the C-ST, I-ST and CE (B). Quantitative measurements of SUVrs to CE in C-ST and I-ST (C). Data are represented as mean \pm SEM. $* p<0.05$ (Wilcoxon test). Abbreviations: 6-OHDA (6-hydroxydopamine), PET (Positron Emission Tomography), DAT (Dopamine Transporter), MRI-Template (Magnetic Resonance Imaging-Template), SUV (Standard Uptake Value), C-ST (Contralateral-Striatum), I-ST (Ipsilateral-Striatum), CE (Cerebellum), SUVr (Standard Uptake Value ratio to CE).

Figure 3. Metabolome score plots following OPLS-DA for striatum (A) $(n=8)$ and PLS-DA for SN (B) $(n=7)$ extract by LC-HRMS targeted analysis. Cerebral structures from the contralateral hemisphere (C-ST and C-SN) are represented by blue circles and structures from the ipsilateral hemisphere (I-ST and I-SN) by red circles. The descriptive and predictive performance characteristics of the models are $R^{2} Y=$ 0.90 and $\mathrm{Q}^{2}=0.78$ for striatum; $\mathrm{R}^{2} \mathrm{Y}=0.84$ and $\mathrm{Q}^{2}=0.53$ for $\mathrm{SN}$. Abbreviations: OPLS-DA (Orthogonal Partial Least Scare-Discriminant Analysis), PLS-DA (Partial Least Scare-Discriminant Analysis), LC-HRMS (Liquid Chromatography-High Resolution Mass Spectrometry), SN (Substantia Nigra), C-ST (Contralateral- 
Striatum), I-ST (Ipsilateral-Striatum), C-SN (Contralateral-Substantia Nigra), I-SN (Ipsilateral-Substantia Nigra).

Figure 4. Autoradiographic studies: analysis of DAT and TSPO with $\left[{ }^{125} \mathrm{I}\right] \mathrm{PE} 2 \mathrm{I}$ and $\left[{ }^{3} \mathrm{H}\right]$ DPA-714 on coronal brain sections of 6-OHDA-lesioned rats $(\mathrm{n}=14)$. Representative total (upper side) and non-specific (lower side) binding of $\left[{ }^{125} \mathrm{I}\right] \mathrm{PE} 2 \mathrm{I}$ in C-ST and I-ST (A). Quantitative measurements of DAT density expressed as specific binding of $\left[{ }^{125} \mathrm{I}\right] \mathrm{PE} 2 \mathrm{I}$ in C-ST and I-ST (B). Representative total (upper side) and non-specific (lower side) binding of $\left[{ }^{3} \mathrm{H}\right] \mathrm{DPA}-714$ in C-ST and I-ST (C). Quantitative measurements of TSPO density expressed as specific binding of $\left[{ }^{3} \mathrm{H}\right] \mathrm{DPA}-714$ in C-ST and I-ST (D). Data are represented as mean \pm SEM. $* * * p=$ 0.0001 (Wilcoxon test). Abbreviations: 6-OHDA (6-hydroxydopamine), DAT (Dopamine Transporter), TSPO (18 kDa Translocator Protein), C-ST (ContralateralStriatum), I-ST (Ipsilateral-Striatum).

Figure 5. Immunofluorescence analysis of TH on coronal brain sections of 6-OHDAlesioned rats $(n=14)$. (A). Representative immunostaining of TH in C-ST and I-ST (B). Quantitative measurements of area occupied by TH in C-ST and I-ST. Data are represented as mean \pm SEM. $* * * p=0.0001$ (Wilcoxon test).

Abbreviations: 6-OHDA (6-hydroxydopamine), TH (Tyrosine Hydroxylase), C-ST (Contralateral-Striatum), I-SN (Ipsilateral-Striatum).

Figure 6. Immunofluorescence studies: analysis of $\mathrm{TH}$ and $\mathrm{CD} 11 \mathrm{~b}$ on coronal brain sections of 6-OHDA-lesioned rats $(n=14)$. Representative immunostaining of TH in C-SN and I-SN (A). Quantitative measurements of TH positive cells in C-SN and I- 
SN (B). Representative immunostaining of CD11b in C-SN and I-SN (C). Quantitative measurements of area occupied by CD11b in C-SN and I-SN (D). Data are represented as mean \pm SEM. $* * * p=0.0001$ (Wilcoxon test). Abbreviations: 6OHDA (6-hydroxydopamine), TH (Tyrosine Hydroxylase), C-SN (ContralateralSubstantia Nigra), I-SN (Ipsilateral-Substantia Nigra). 


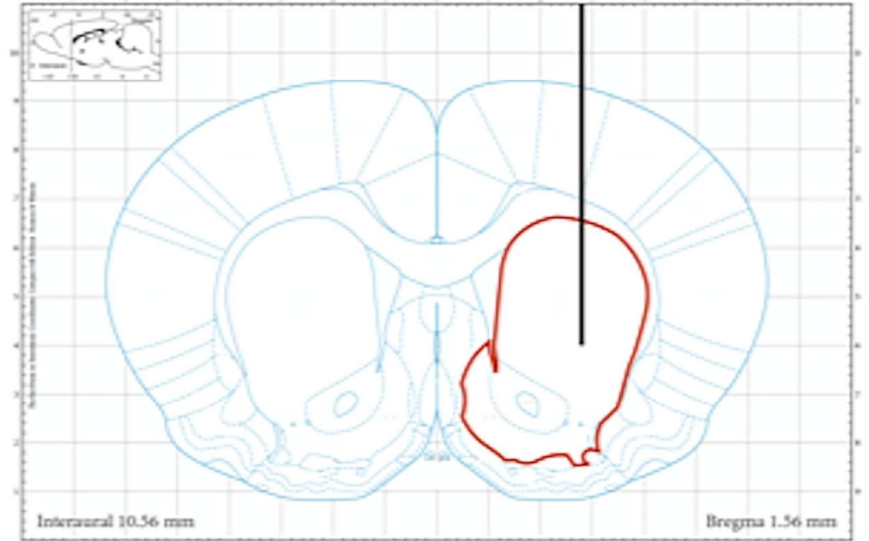

$\mathrm{AP} 1=+1.6 \mathrm{~mm} ; \mathrm{L} 1=-2.8 \mathrm{~mm} ; \mathrm{P} 1=-6 \mathrm{~mm}$

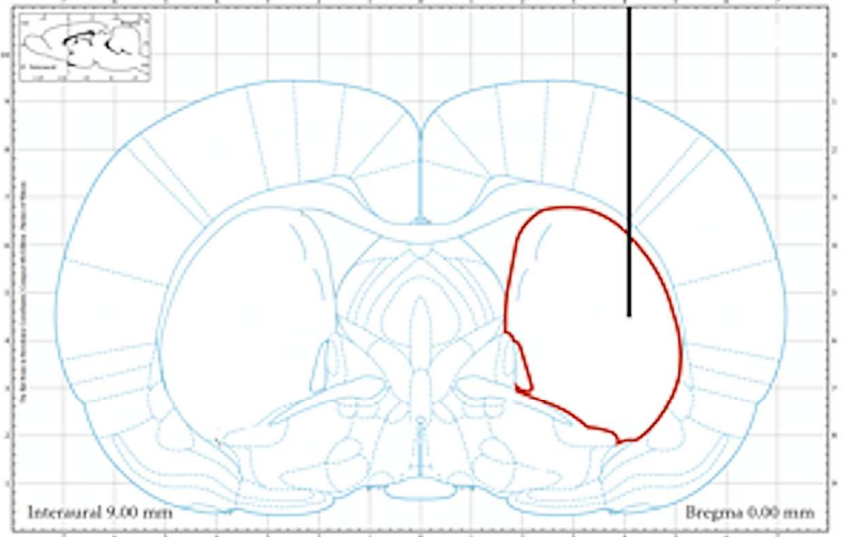

$\mathrm{AP2}=0.0 \mathrm{~mm} ; \mathrm{L} 2=-4.1 \mathrm{~mm} ; \mathrm{P} 2=-5.5 \mathrm{~mm}$

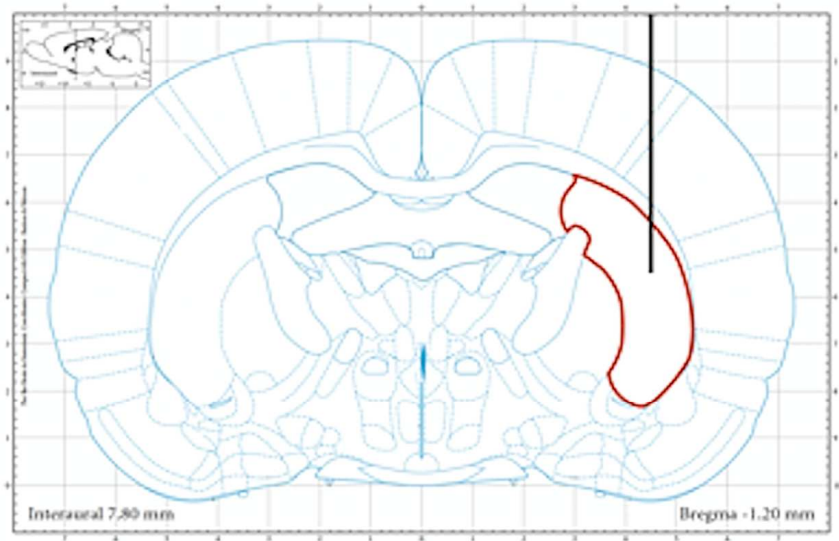

$\mathrm{AP} 3=-1.2 \mathrm{~mm} ; \mathrm{L} 3=-4.5 \mathrm{~mm} ; \mathrm{P} 2=-5.5 \mathrm{~mm}$ 
(A)

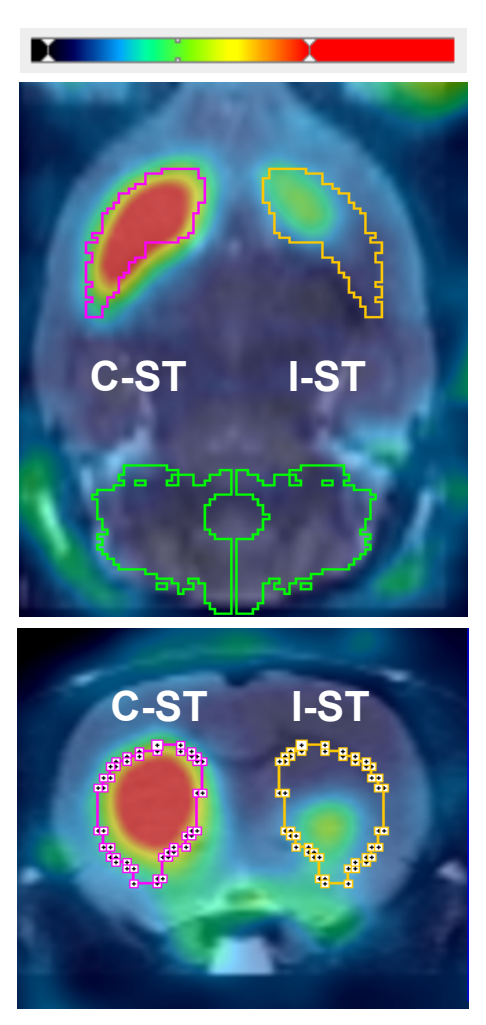

(B)

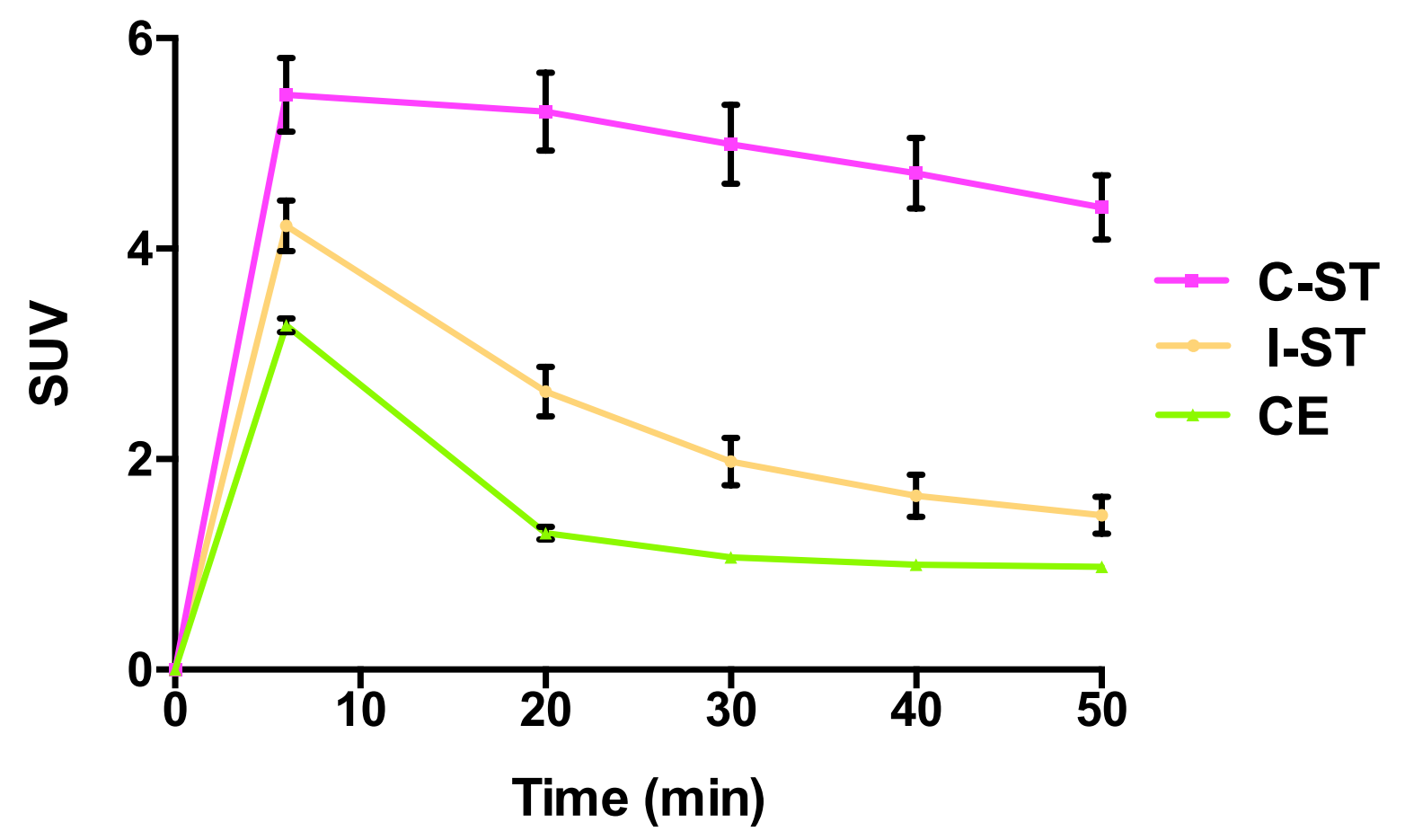

(C)

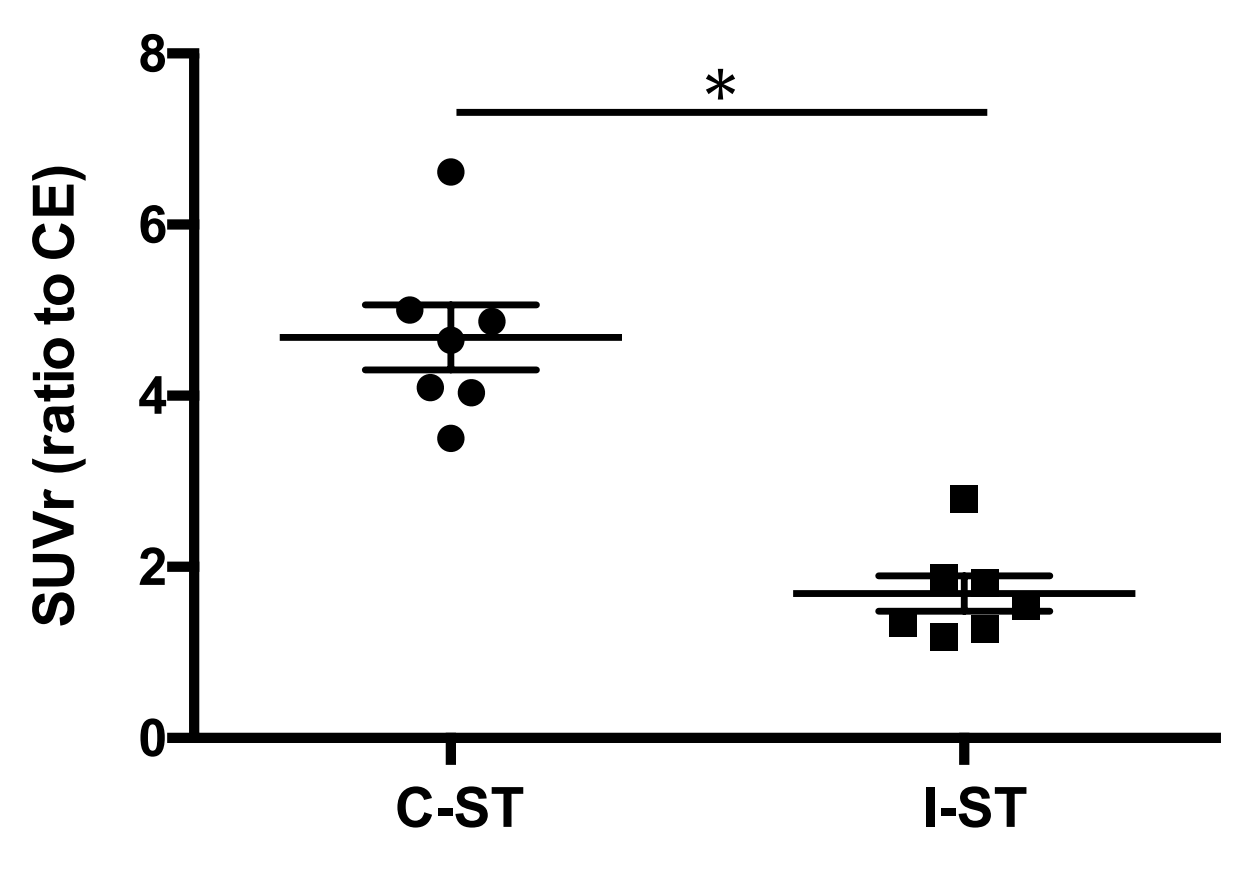



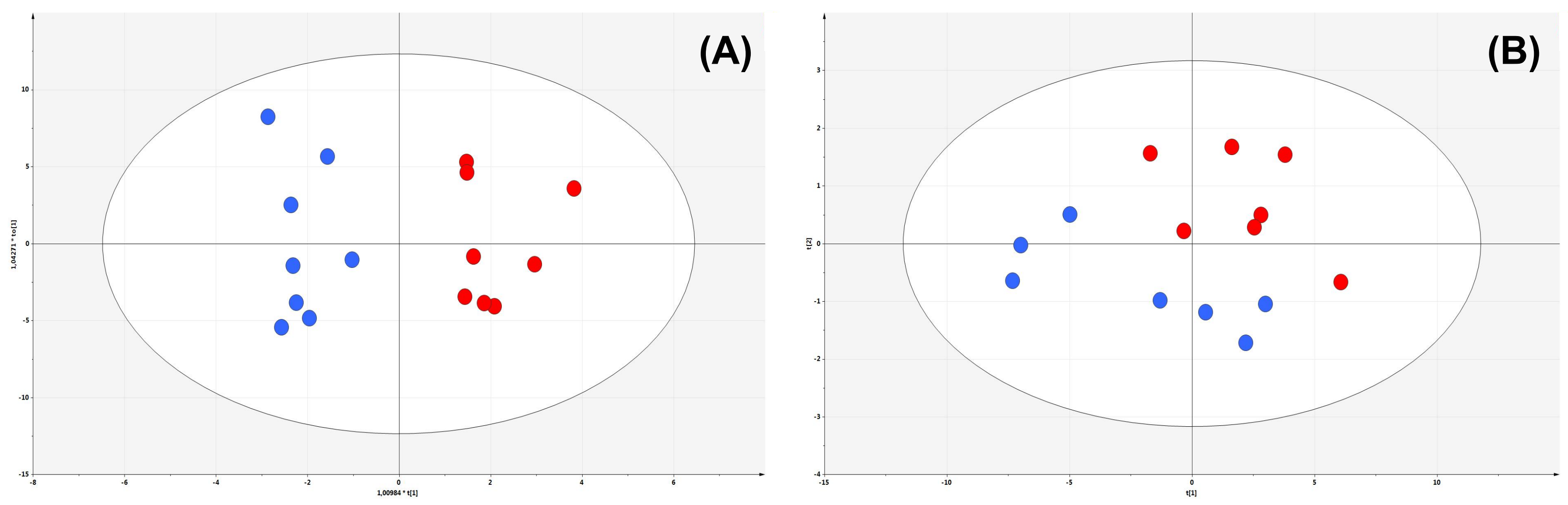
(A)

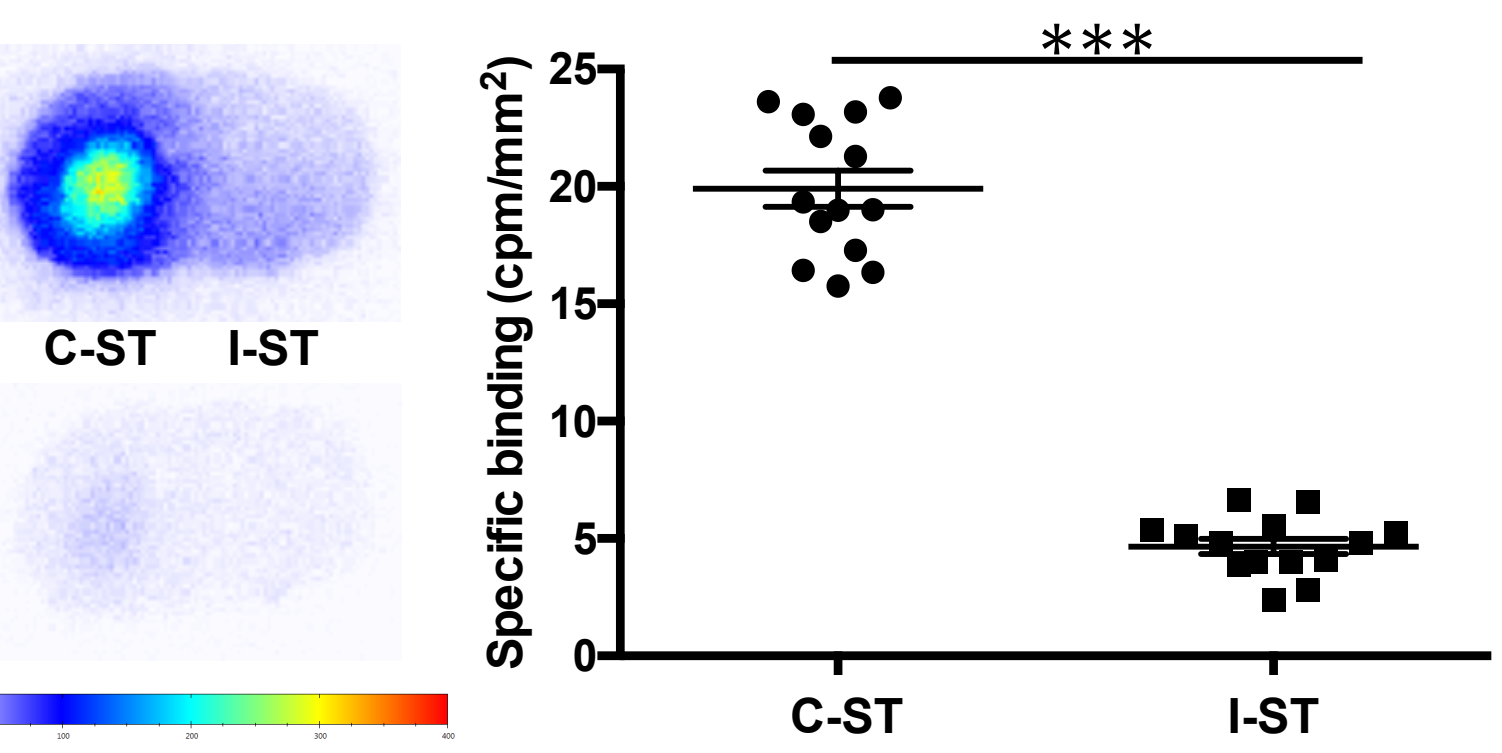

(C)

(D)

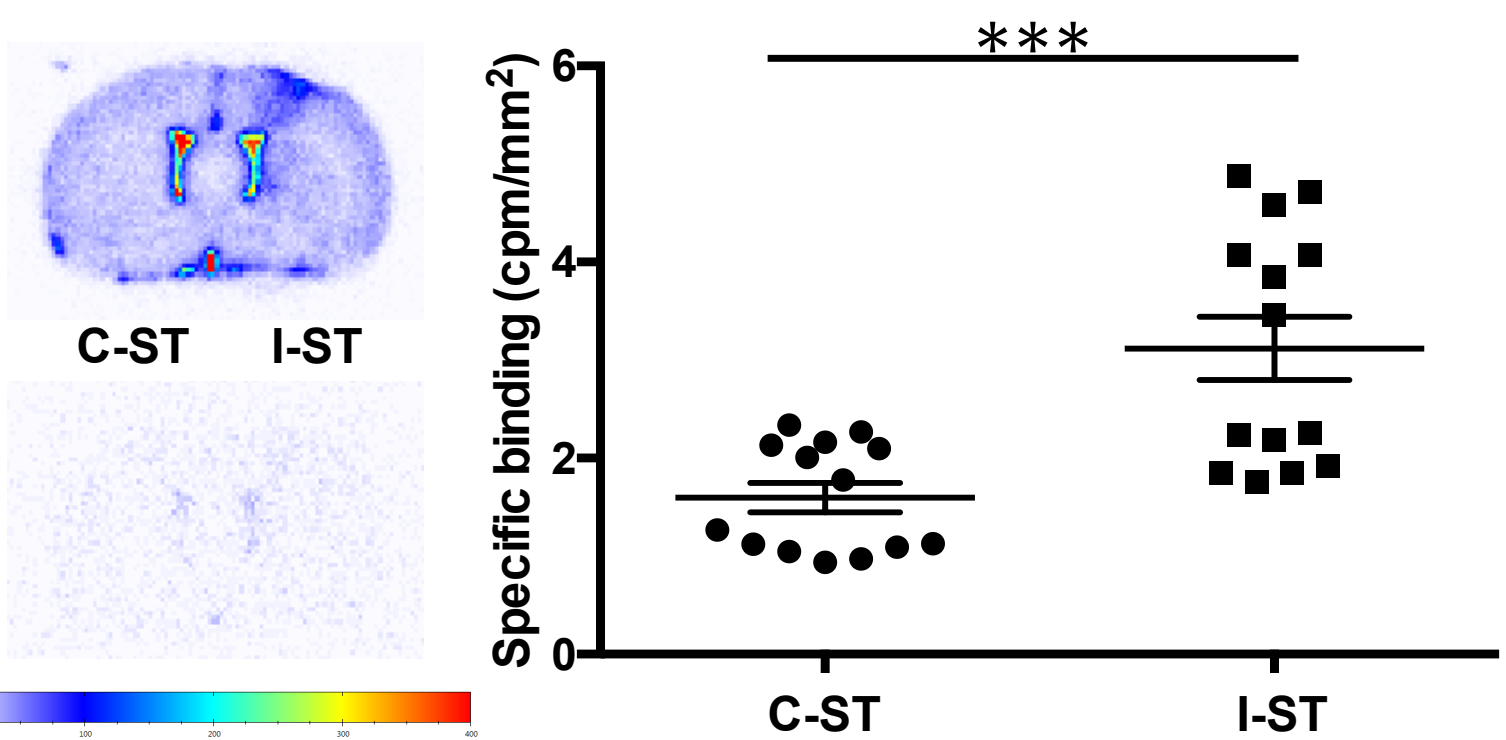


(A)
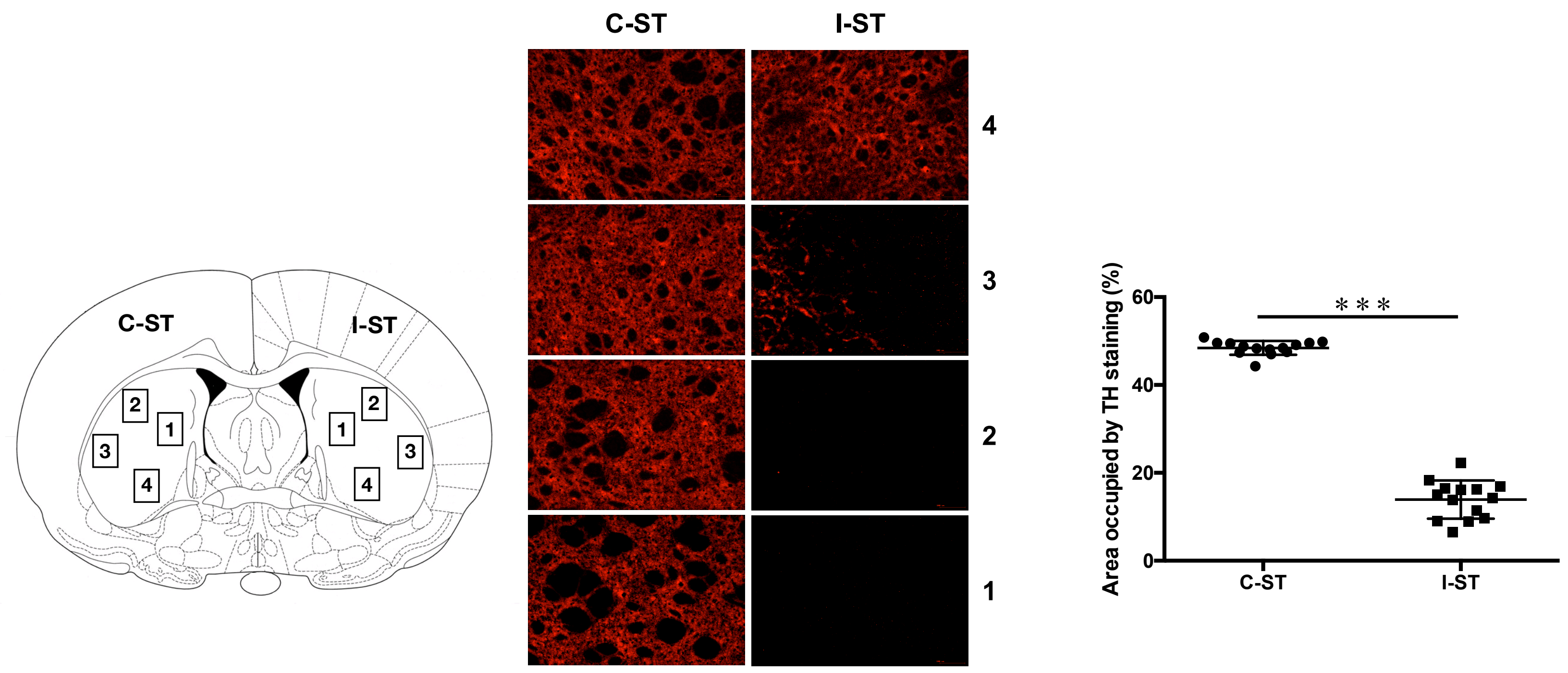
(A)

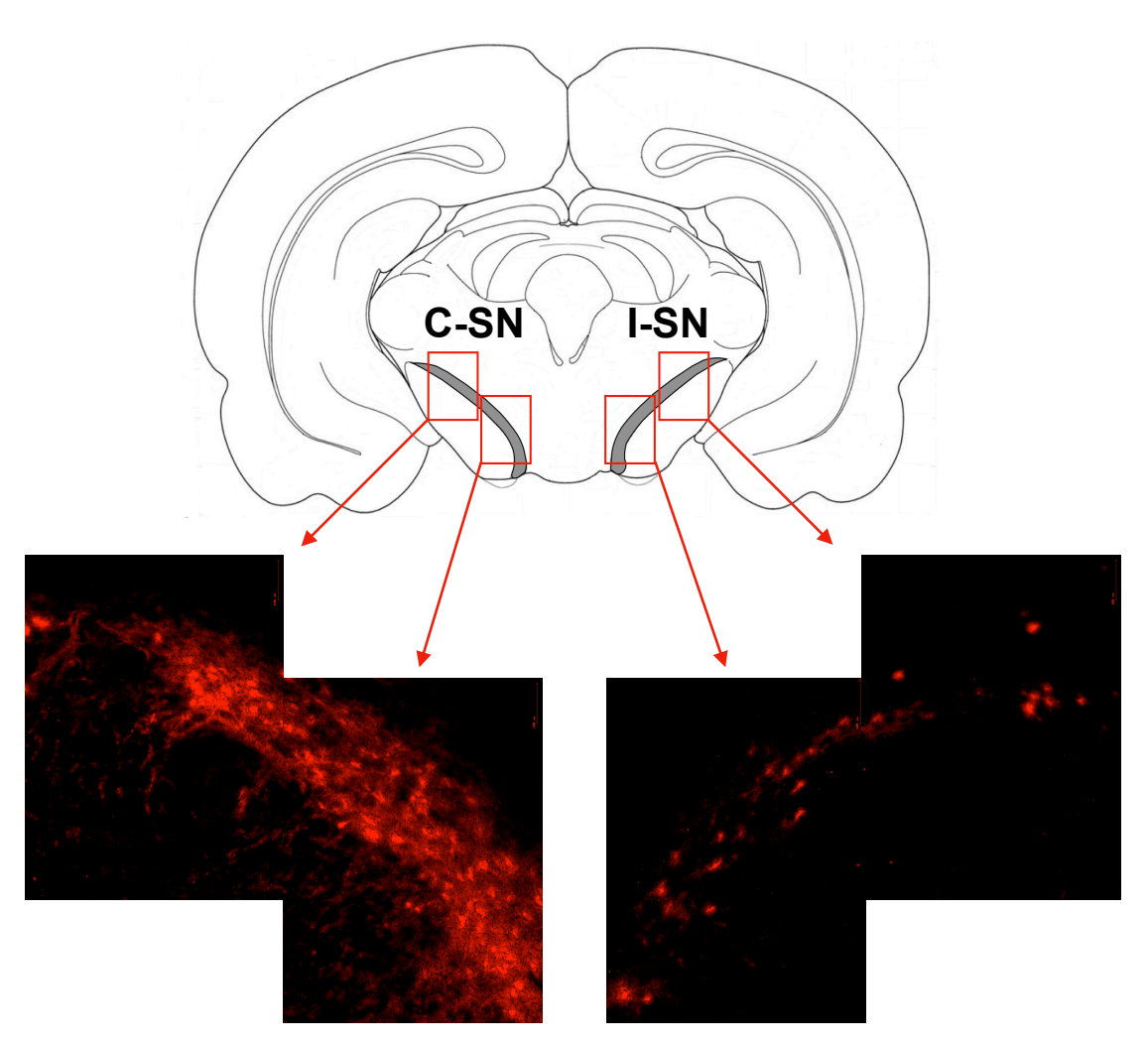

(B)

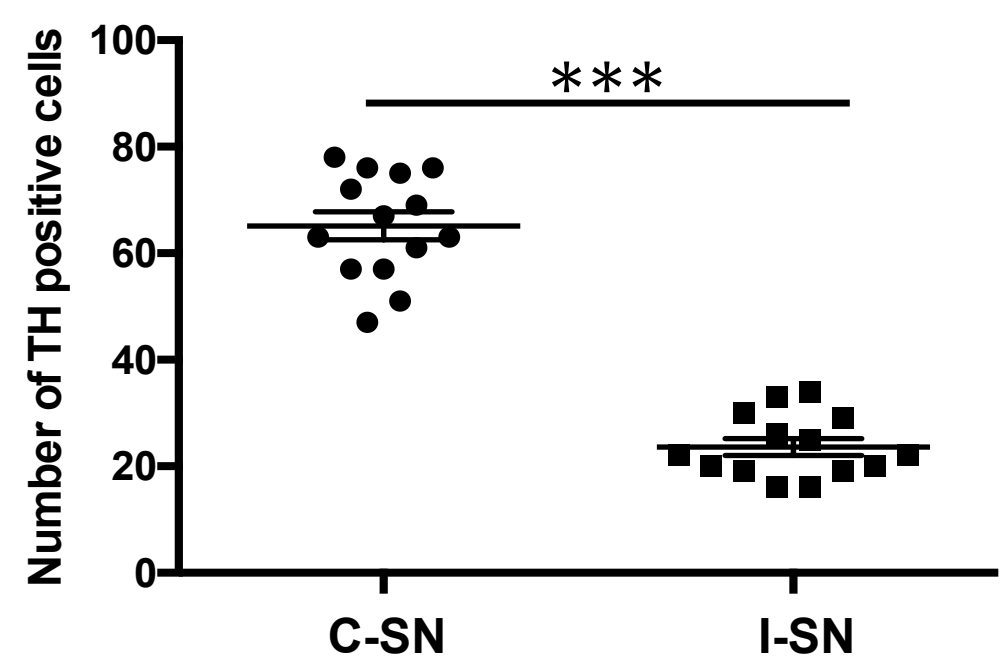

(C)

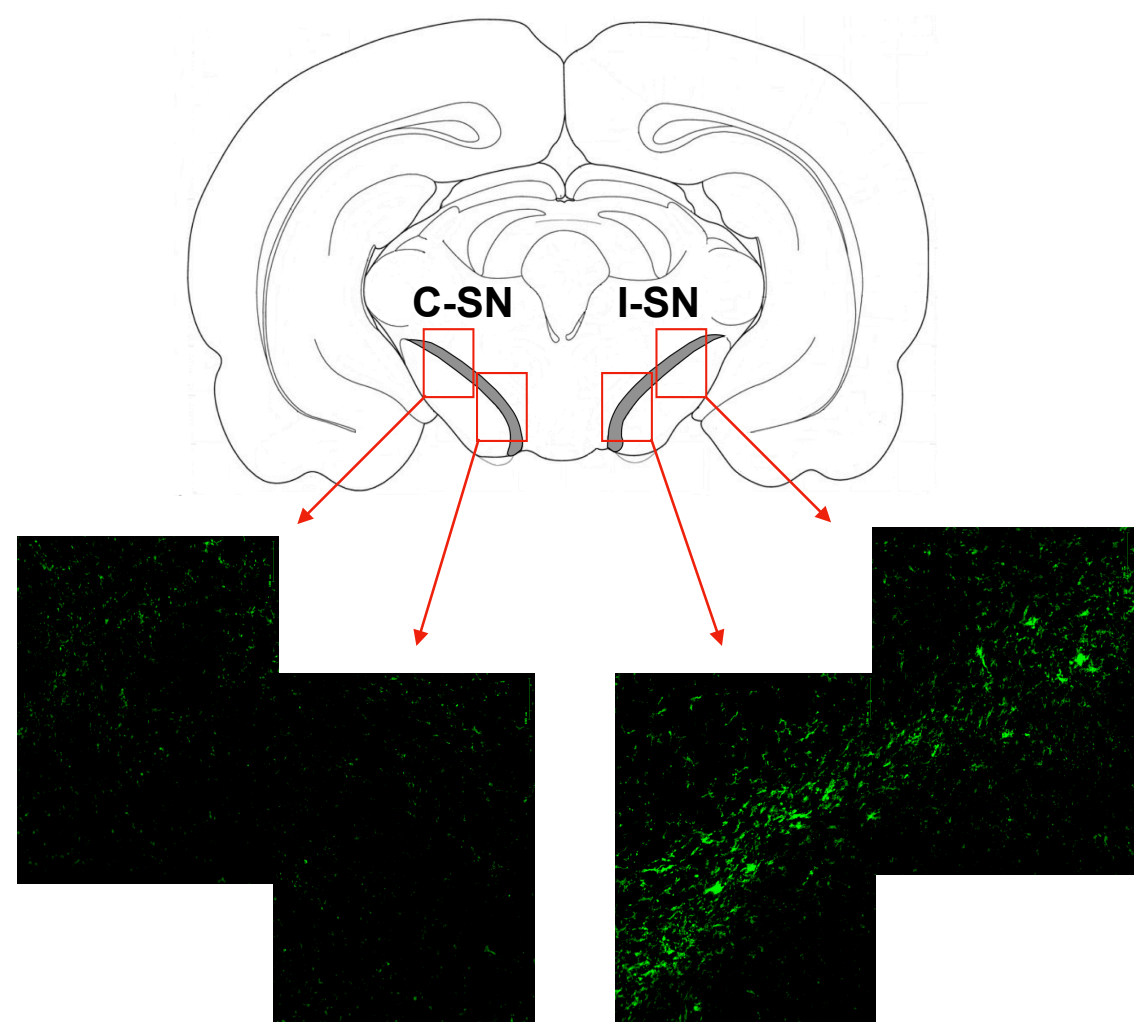

(D)

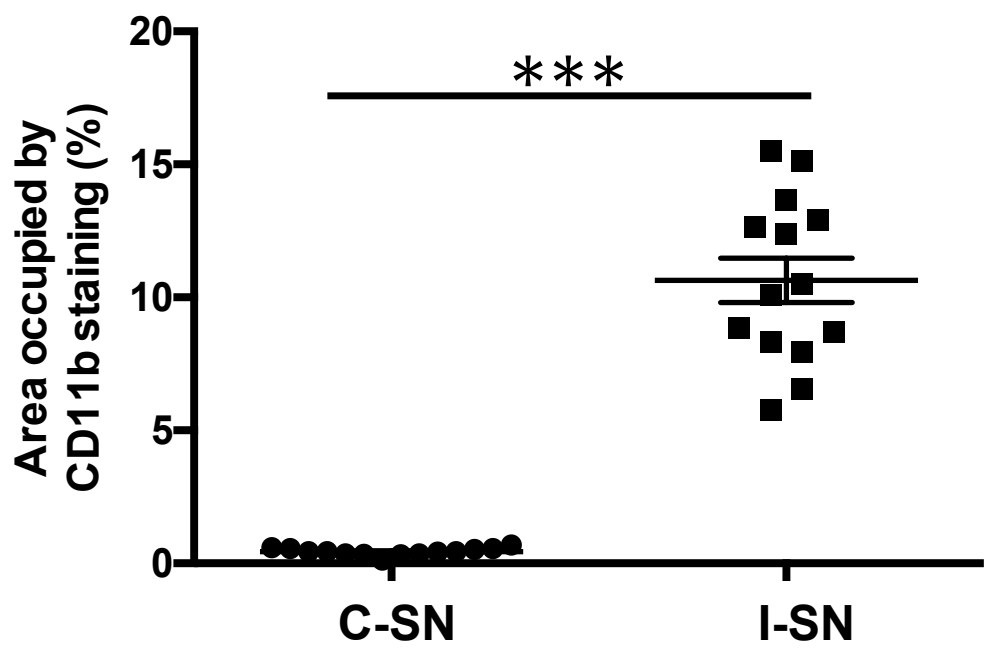




\begin{tabular}{|c|c|c|c|}
\hline Metabolite & VIP score & FC ratio & $p$-value \\
\hline \multicolumn{4}{|c|}{ Striatum } \\
\hline Dopamine & 2.37 & 0.44 & 0.002 \\
\hline Glucose-1-phosphate & 0.53 & 0.58 & 0.038 \\
\hline L-Carnitine & 1.91 & 1.32 & 0.001 \\
\hline Indole-3-acetic acid & 2.28 & 0.56 & 0.007 \\
\hline \multicolumn{4}{|c|}{ SN } \\
\hline Glucose-6-phosphate & 0.93 & 0.57 & 0.037 \\
\hline
\end{tabular}

